\title{
Effect of PWHT on Laser-Welded Duplex Stainless Steel
}

\author{
The effects of postweld heat treatments on the microstructure, tensile behavior, \\ and corrosion resistance of laser-welded duplex stainless steel were investigated
}

\author{
BY A. S. MAGALHÃES, C. H. X. M. MAGALHÃES, M. S. F. DE LIMA, J. CRUZ, L. B. GODEFROID, R. BERTAZZOLI, AND G. L. DE FARIA
}

\begin{abstract}
The welded joints of duplex stainless steels (DSSs) have been widely used in petrochemical, nuclear, pulp, and paper industries. Welds require a good, superficial finishing and a combination of mechanical and corrosion properties in these types of high-quality, demanding applications. Even though laser welding promotes narrow weld beads and a small heataffected zone, when it is applied to DSSs, it can produce dangerous microstructural discontinuities. In this context, the effects of subsequent heat treatments on the microstructure, corrosion resistance, microhardness, and tensile properties of DSS laser-welded joints are investigated. In this study, samples of UNS S32304 DSS were submitted to two different conditions of laser welding. Subsequently, the plates submitted to the best welding condition were subjected to isothermal heat treatments at different temperatures $\left(850^{\circ}\right.$, $950^{\circ}, 1050^{\circ}$, and $1150^{\circ} \mathrm{C}$ ) for $10 \mathrm{~min}$. Then they were microstructurally characterized. Phase fraction measurements and microhardness tests were performed. Based on the obtained results, postweld heat-treated samples at $1150^{\circ} \mathrm{C}$, which is the best condition, were subjected to corrosion and tensile tests. It was possible to conclude the corrosion properties of the welded joint were significantly improved after the heat treatment. However, the mechanical behavior was strongly influenced by the presence of volumetric discontinuities and intermetallic compounds, which considerably deteriorated the mechanical strength of the material.
\end{abstract}

\section{KEYWORDS}

- Laser Welding • Duplex Stainless Steel • Corrosion

- Postweld Heat Treatment

\section{Introduction}

Duplex stainless steels (DSSs) are dual-phase alloys based on the $\mathrm{Fe}-\mathrm{Cr}-\mathrm{Ni}$ system, whose microstructure consists of similar volume ferrite and austenite fractions, containing approximately $50 \%$ of each phase (Ref. 1). DSSs have advantages over austenitic and ferritic stainless steels because they have a favorable property combination of both steels: good toughness, high mechanical strength, good corrosion resistance in different environments, excellent fatigue strength, and stress corrosion cracking resistance (Ref. 2). Due to their properties, DSSs have been used in the petrochemical, oil and gas, pulp, and other types of industry. Furthermore, they are commonly used in aqueous and chloridecontaining environments, and as a substitute for austenitic stainless steels, which may suffer chloride corrosion under stress or pitting in service (Ref. 3).

In most applications, DSSs must undergo a welding process. During this process, the microstructure and properties of the DSSs can be significantly changed. The volume fractions of ferrite/austenite phases become unbalanced when close to the heat-affected zone (HAZ), and a structure constituted for almost $100 \%$ of ferrite can be formed near the fusion central line. In addition, precipitation of intermetallic compounds may occur (Refs. 1, 3). The effects of these structural changes on the mechanical and corrosion properties of DSSs can be deleterious (Ref. 4). According to Nilsson (Ref. 5), the chromium nitride precipitation in the ferrite decreases the material pitting corrosion resistance. Kordatos et al. (Ref. 6) claim these precipitates also contribute to the toughness decrease in samples that are fastwater cooled after the welding procedure. Consequently, welding processes have been extensively analyzed to minimize the deleterious effects on the mechanical properties and corrosion resistance of DSSs due to the welding thermal cycles (Ref. 7).

Laser welding has proven to be an attractive process for the joining of thin steel plates because it has high productivity. In addition, it is characterized by its small HAZ, deep penetration, narrow weld bead, low-heat input per volume unit, and high degree of automation. However, laser welding in DSSs promotes the presence of a metastable structure al- 


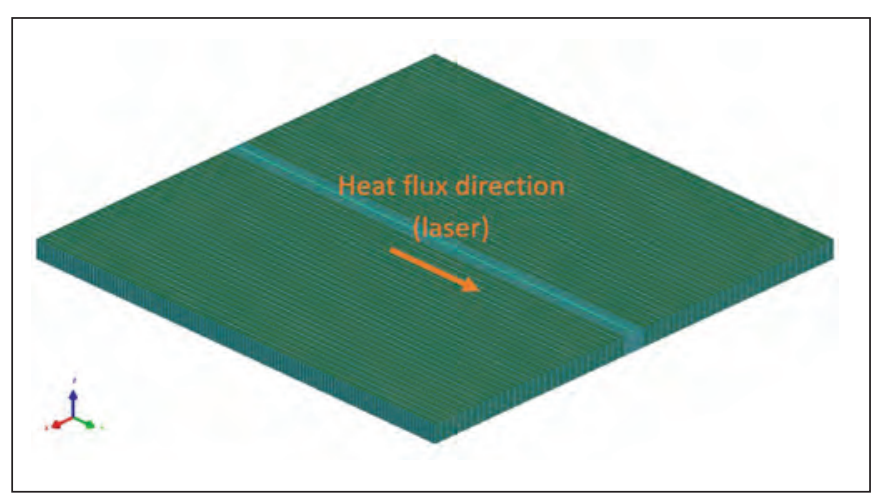

Fig. 1-Three-dimensional model employed at SYSWELD.

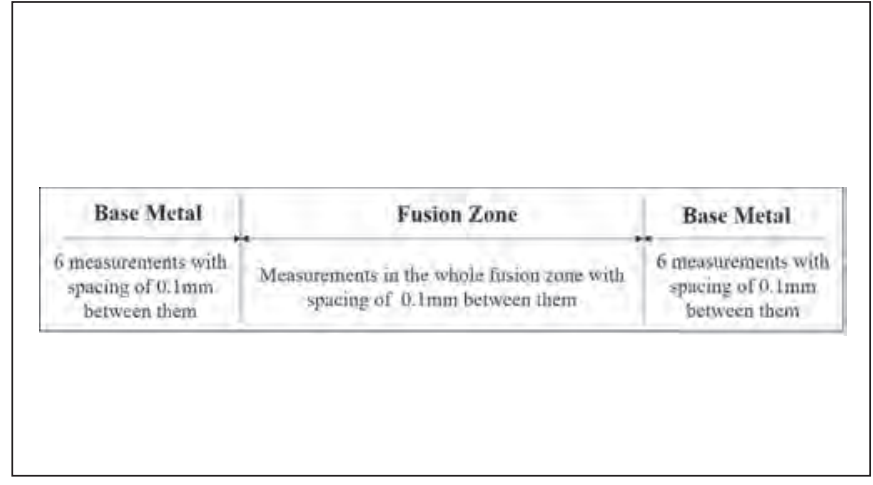

Fig. 2 - Microhardness measurement scheme.

Table 1 - Chemical Composition of UNS $\$ 32304$ Steel (wt-\%)

\begin{tabular}{ccccccccccc}
$\mathrm{C}$ & $\mathrm{Mn}$ & $\mathrm{Si}$ & $\mathrm{Cr}$ & $\mathrm{Ni}$ & $\mathrm{P}$ & $\mathrm{S}$ & $\mathrm{Cu}$ & $\mathrm{Mo}$ & $\mathrm{N}$ \\
\hline 0.01 & 1.34 & 0.31 & 22.23 & 4.10 & 0.025 & 0.0004 & 0.09 & 0.32 & 0.10 \\
\hline
\end{tabular}

most completely ferritic in the fusion zone (FZ), consisting of elongated ferrite grains with a small amount of allotriomorphic and Widmanstätten austenites, and abundant precipitation of chromium nitrides due to the high cooling rates arising from the procedure (Refs. 8, 9).

According to previous studies, an effective way to improve the DSSs weldability is to adjust the austenite volumetric fraction in the FZ, reformatting the austenite and, if possible, reestablishing its morphology (Ref. 10). The laser welding procedure and the postweld heat treatments (PWHTs) applied to DSSs are not as well studied as the other usual welding methods (Refs. 11-15). Even so, there is an indication that the correct planning and use of PWHT can be a powerful tool for this purpose, resulting in desirable mechanical and corrosion properties in the FZ. In this context, this study aims to evaluate the effects of PWHTs on the microstructure, tensile behavior, and corrosion resistance of laser-welded UNS S32304 duplex stainless steel.

\section{Experimental Procedure}

\section{Material}

The as-received UNS S32304 duplex stainless steel plates were supplied by Aperam South America. Table 1 shows the chemical composition provided by the manufacturer. The samples were taken from a cold-rolled sheet with a $48 \%$ area reduction and a $2.5-\mathrm{mm}$ final thickness, annealed and pickled with $2 \mathrm{~B}$ finishing rolling (dimensional fine adjustment and strain hardening rolling).

Plates of UNS S32304 duplex stainless steel, with dimensions of $6.5 \times 6.5 \mathrm{~cm}$, were laser welded in a butt joint configuration in the rolling direction. A high-powered fiber laser, manufactured by IPG Photonics Ltd., model YLR2000W was used. This laser has a maximum power of 2000 $\mathrm{W}$ in continuous operation. Argon and nitrogen were used as the shielding and process gas, respectively. The flow rate of argon gas was $8 \mathrm{~L} / \mathrm{min}$. The plates were placed under the welding table with a computer numerical control managed by the software $\mathrm{EMC}^{2}$ operated by the Linux system (Ref. 16), which allows for variation in the speed and position of the laser. The studied welding conditions were as follows: 1) AT50, performed at a speed of $2400 \mathrm{~mm} / \mathrm{min}$ and a power of $2000 \mathrm{~W}$, and 2) AT100, performed at a speed of $600 \mathrm{~mm} / \mathrm{min}$ and a power of $1000 \mathrm{~W}$.

\section{Computational Simulation of the Welding Thermal Profile}

Because there is great difficulty in measuring temperatures during laser welding, it was necessary to use numerical methods to evaluate the thermal gradients to which the plates were subjected during the process. In the present study, ESS Group's SYSWELD software was used to investigate the effect of the welding conditions on the thermal cycling imposed on the plates (Ref. 17).

The SYSWELD software has an extensive database of metallic material properties, which allows an estimation of the thermometallurgical and mechanical characteristics of the component during and after welding. The thermal properties of the UNS S32304 DSS are not part of the software database, so it is necessary to use the material whose thermal conductivity, specific heat, and density are as close as possible to the studied material. In this case, the properties of 316L stainless steel were used.

The simulation was based on a three-dimensional finite element model in which a mesh was constituted of 140,000 nodes with tetrahedral elements, and was inserted, as presented in Fig. 1. Note that the mesh is refined around the path of the heat source to improve the resolution where the thermal gradient is larger. As the thermal transfer is performed through the nodes between each element of the mesh, the minimum distance between the nodes was $0.03 \mathrm{~mm}$ in the $\mathrm{x}$ axis and $0.25 \mathrm{~mm}$ in the $\mathrm{z}$-axis, around the heat source.

For the computational simulation, the same values for the welding power and speed used in the already described physical experiments, and a laser beam absorptivity of $65 \%$, were used (Ref. 18). It must be noted that the ab- 
Table 2 - Heat Treatment Temperatures

Temperature of Isothermal

Heat Treatment (10 min)

Identification

$\begin{array}{ll}850^{\circ} \mathrm{C} & \mathrm{L} 1 \\ 950^{\circ} \mathrm{C} & \mathrm{L} 2 \\ 1050^{\circ} \mathrm{C} & \mathrm{L} 3 \\ 1150^{\circ} \mathrm{C} & \mathrm{L} 4\end{array}$

sorptivity was a fit for the simulation and not based upon any experimentally determined data. This absorptivity was estimated/ fit in a way that the simulated shape of the melt pool corresponded to the dimensions experimentally verified. The calorimetric procedure for estimation of the absorptivity could not be applied in the current setup due to the dimensions of the sample (Ref. 19). In the present study, the output data of the computational simulation were the temperature profiles as a function of the time for both studied experimental conditions, which are called AT50 and AT100.

Because it is difficult to monitor the temperature in laser welding processes, the measured width of the FZ as a validation parameter for the computational model was utilized as it will be shown in the results.

\section{PWHT}

For PWHTs to be practical and economically feasible in the industrial manufacturing routine, it is important that a relatively short time be adopted during this procedure.

Thus, some plates welded using the AT100 condition were subjected to isothermal heat treatments for $10 \mathrm{~min}$ in a furnace manufactured by the Instituto de Aeronáutica e Espaço, AMR - Divisão de Materiais. Then, they were cooled in water at room temperature. Table 2 presents the temperatures used and the sample identification nomenclature.

\section{Microstructural Characterization and Phase Fraction Measurements}

Samples of the welded plates were examined in the transverse direction (through thickness) of the weld bead for analysis by the optical microscope (OM). The samples were prepared for metallographic examination, according to the ASTM E3-11 standard recommendations (Ref. 20). For phase volume fraction quantification, the samples were etched by Beraha II etchant (20-mL HCl, 80-mL $\mathrm{H}_{2} \mathrm{O}, 1-\mathrm{g}$ $\mathrm{K}_{2} \mathrm{~S}_{2} \mathrm{O}_{5}$, 2. [Refs. 21-26]). The volumetric fractions of ferrite and austenite were determined by automatic image analysis software LAS-LEICA by a complete scan of the FZ image (200x magnification). The characterization of the FZ and base metal (BM) was carried out by the OM. For this purpose, the samples were electrolytically etched with the $\mathrm{KOH}$ solution (100-g KOH and 900-mL deionized water) by applying $3 \mathrm{~V}$ for $30 \mathrm{~s}$. Then, some samples were electrolytically etched by using a $10 \%$ oxalic acid solution by applying $3 \mathrm{~V}$ for $30 \mathrm{~s}$ to reveal chromium nitrides. Additionally, the following three techniques were also performed to enhance the microstructural characterization and phase quantification.

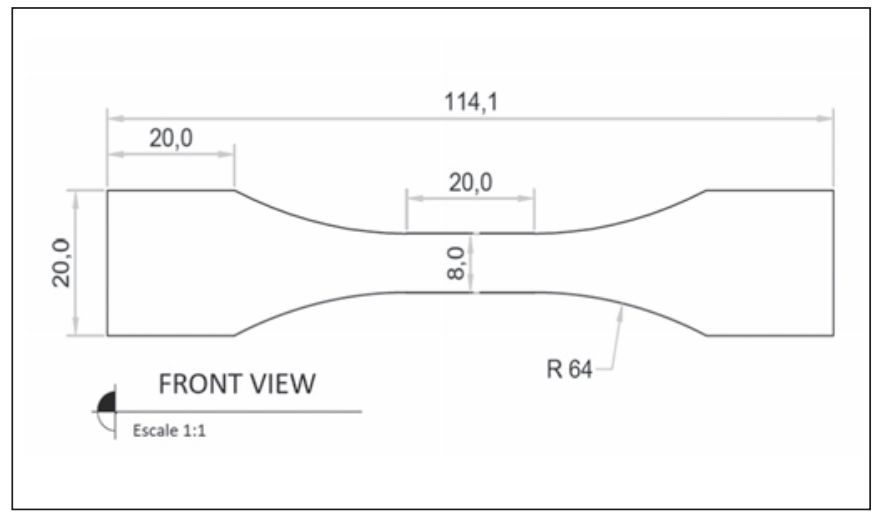

Fig. 3 - Dimensions of the specimens used in the tensile tests (in $\mathrm{mm}$ ).

\section{Electron Backscatter Diffraction Analysis}

To confirm the phase identification (austenite and ferrite) performed in the previous procedure and to compare the phase quantification performed by the OM and electron backscatter diffraction (EBSD), as-received AT100 and L4 samples were analyzed via EBSD. For analyses via EBSD, the samples followed the same procedures of metallographic sample preparation for the $\mathrm{OM}$ with an additional $1.5 \mathrm{~h}$ of polishing with $0.02 \mu \mathrm{m}$ colloidal silica on a Minimet Buehler polishing machine. EBSD analysis was performed on the Vega 3 - Tescan scanning electron microscope (SEM) and the analysis software was AZtec Oxford.

\section{SEM Analysis}

For further investigation of precipitation of chromium nitrides in the ferritic grain boundaries in the FZ of the AT50 sample, SEM analyses were executed by a Vega 3 - Tescan SEM. The sample was prepared following the same metallographic procedures for the OM. Then, based on literature data and on ASTM A1084, Standard Test Method for Detecting Detrimental Phases in Lean Duplex Austenitic/Ferritic Stainless Steels, two etchants were adopted to reveal evidences of the presence of chromium nitrides precipitates: $10 \%$ oxalic acid solution by applying $3 \mathrm{~V}$ for $30 \mathrm{~s}$ (indirect evidence due to sensitization occurrence where chromium nitrides precipitate) and Beraha II etchant (20-mL $\mathrm{HCl}, 80$ $\mathrm{mL} \mathrm{H} \mathrm{H}_{2} \mathrm{O}$, 1-g K $\mathrm{K}_{2} \mathrm{~S}_{5}$, 2.4-g $\left(\mathrm{NH}_{4}\right) \mathrm{HSO}_{4}$ ) for $10 \mathrm{~s}$ (direct evidence due to the revelation of nanostructured chromium nitrides) (Refs. 27, 28).

\section{Transmission Electron Microscopy Analysis}

To verify the presence of chromium nitrides, transmission electron microscopy (TEM) analysis was performed. For that, the FZ of the AT100 sample was previously prepared by the focused electron beam (FIB) technique in a Quanta 3D field emission gun FEI SEM. Through the cut performed by the FIB, a wedge-shaped sample was obtained in the dimensions of $4 \times 2 \mathrm{~mm}$ and thickness of less than $200 \mathrm{~nm}$, hence the TEM analysis could be performed. TEM was carried out with the aid of the Tecnai G2-20 SuperTwin FEI, 200-kV TEM. 


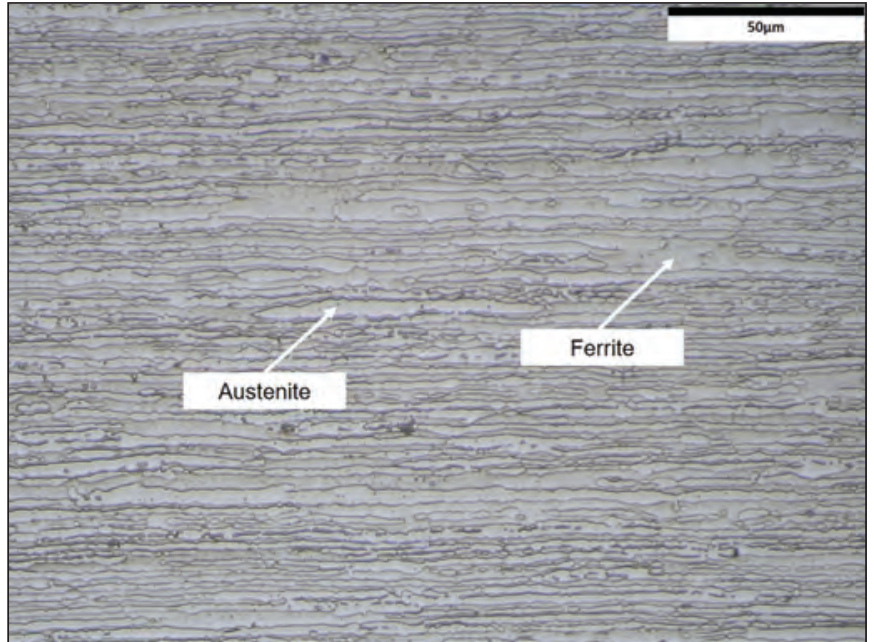

Fig. 4 - Microstructure of UNS $S 32304$ DSS. KOH electrolytic etching. $0 \mathrm{M}-500 \mathrm{x}$

\section{Porosity Measurement in the Fusion Zone}

The used measurement method was the light OM cross sections. Several OM images of the FZ cross section were submitted to image analyses, and the total pore area, in $\mu \mathrm{m}^{2}$, were measured $\left(\mathrm{S}_{\mathrm{p}}\right)$, as well as the FZ total area $\left(\mathrm{S}_{\mathrm{FZ}}\right)$. This method consisted of calculating the average relative pore area in relation to the FZ area [P (\%)] (Eq. 1). Qualitative sampling ensured a R.A. value, i.e., relative accuracy of less than 5\% (Ref. 29).

$P(\%)=S_{p} / S_{F Z}$

\section{Vickers Microhardness and Ultramicrohardness Measurements}

To evaluate the effects of welding and the PWHT on FZ and BM, Vickers microhardness measurements were performed on the etched cross section of the welded samples AT100, L1, L2, L3, and L4. For this, a Pantec digital microhardness tester was used with a load of $0.1 \mathrm{kgf}$ holding for $5 \mathrm{~s}$. The hardness of the $\mathrm{BM}$ and $\mathrm{FZ}$ were considered as the average values calculated from several measurements performed in each area. Figure 2 shows a schematic figure that highlights the hardness profiles planning for all studied samples.

To verify the differences between ferrite and austenite specific hardness values and to evaluate if there is some influence of welding and heat treatment performed at $1150^{\circ} \mathrm{C}$ on the phase hardness, Vickers ultramicrohardness measurements were performed on AT100 and L4 samples. These samples were selected because they presented the most appropriate microstructure, considering the need and the desire to obtain similar amounts of austenite and ferrite as the main criterion. The test was performed by a Shimadzu DUH-211/DUH-211S dynamic ultramicrohardness tester with a load of $0.005 \mathrm{kgf}$ holding for $5 \mathrm{~s}$. The average values were calculated from five measurements performed in each phase.

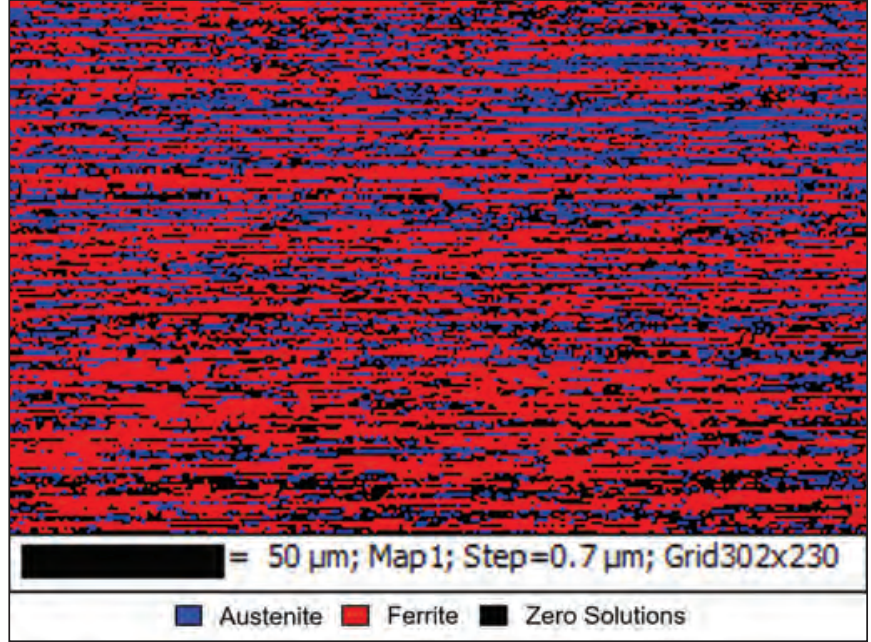

Fig. 5-EBSD map confirming the phase identification determined by the OM in the as-received sample.

\section{Corrosion Tests}

The samples AT100 and L4 were submitted to a corrosion test with microarea analyses. The potentiostat used to measure the open circuit potential (OCP) curves and polarization curves was the Metrohm Autolab model PG-

STAT204. Three electrodes were used in the investigation: the working electrode (the specimen), the tungsten reference electrode with a $125 \mu \mathrm{m}$ diameter and oxidized in 0.1 $\mathrm{mol} / \mathrm{L}$ solution of sulfuric acid from potentials, 0.954 to $1.854 \mathrm{~V}$ in relation to the saturated $\mathrm{Ag} / \mathrm{AgCl}$ electrode, and the platinum counter electrode with a $100 \mu \mathrm{m}$ diameter. The tests were carried out under a controlled atmosphere with a relative humidity of $78 \pm 4 \%$. All analyses were performed in a Faraday cage.

A precision syringe was used to deposit about $30 \mu \mathrm{l}$ of $3.5 \% \mathrm{NaCl}$ solution under a PET laser-cut adhesive mask to demarcate the analyzed area. The exposed surface area analyzed was approximately $0.077 \mathrm{~mm}^{2}$, corresponding to a radius of approximately $157 \mu \mathrm{m}$. The BM and the FZ of each sample were analyzed. The samples underwent OCP stabilization for $30 \mathrm{~min}$, followed by a polarization test starting from -0.1 to $1.2 \mathrm{mV}$ in relation to the oxidized tungsten electrode $-243 \mathrm{mV}$ vs. $\mathrm{Ag} / \mathrm{AgCl}$ ) at a potential scanning rate of $1 \mathrm{mVs}^{-1}$ and with a step size of $0.2 \mathrm{mVs}^{-1}$.

\section{Tensile Tests}

Three conditions were chosen for the tensile test: asreceived steel, laser welded (AT100), and postweld heat treated at $1150^{\circ} \mathrm{C}(\mathrm{L} 4)$. The tensile test specimens were adapted from a fatigue test specimen standard (ASTM E466-15, Standard Practice for Conducting Force Controlled Constant Amplitude Axial Fatigue Tests of Metallic Materials) by conventional machining. The dimensions of the specimens (in $\mathrm{mm}$ ) are shown in Fig. 3.

The tensile tests were performed on a MTS servohydraulic machine using displacement control with a displacement rate of $5 \mathrm{~mm} / \mathrm{min}$ at room temperature until the specimen fractured. Three specimens were used for each sample 

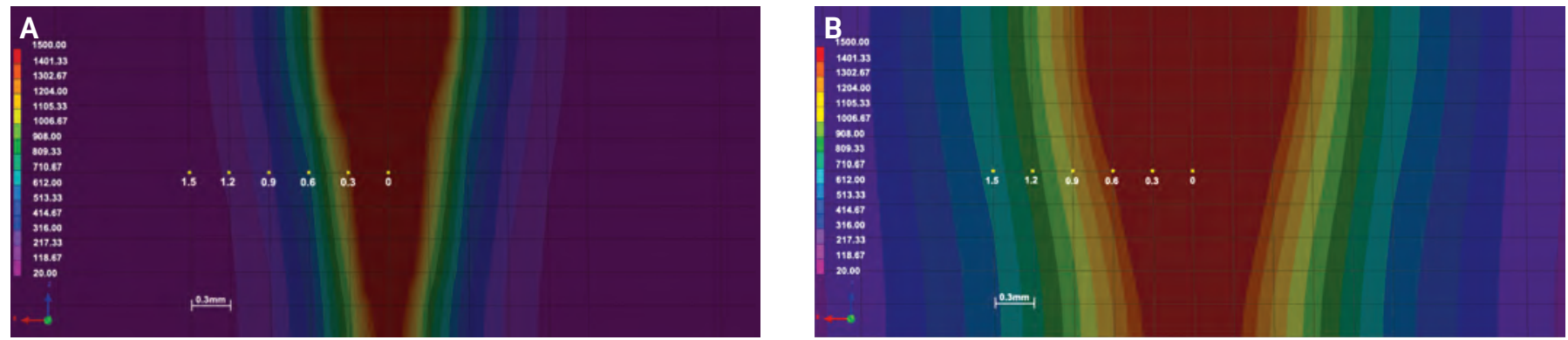

Fig. 6 - Temperature profile (in ${ }^{\circ} \mathrm{C}$ ) as a function of the displacement relative to the center of the FZ: A - AT50; B - ATOO.
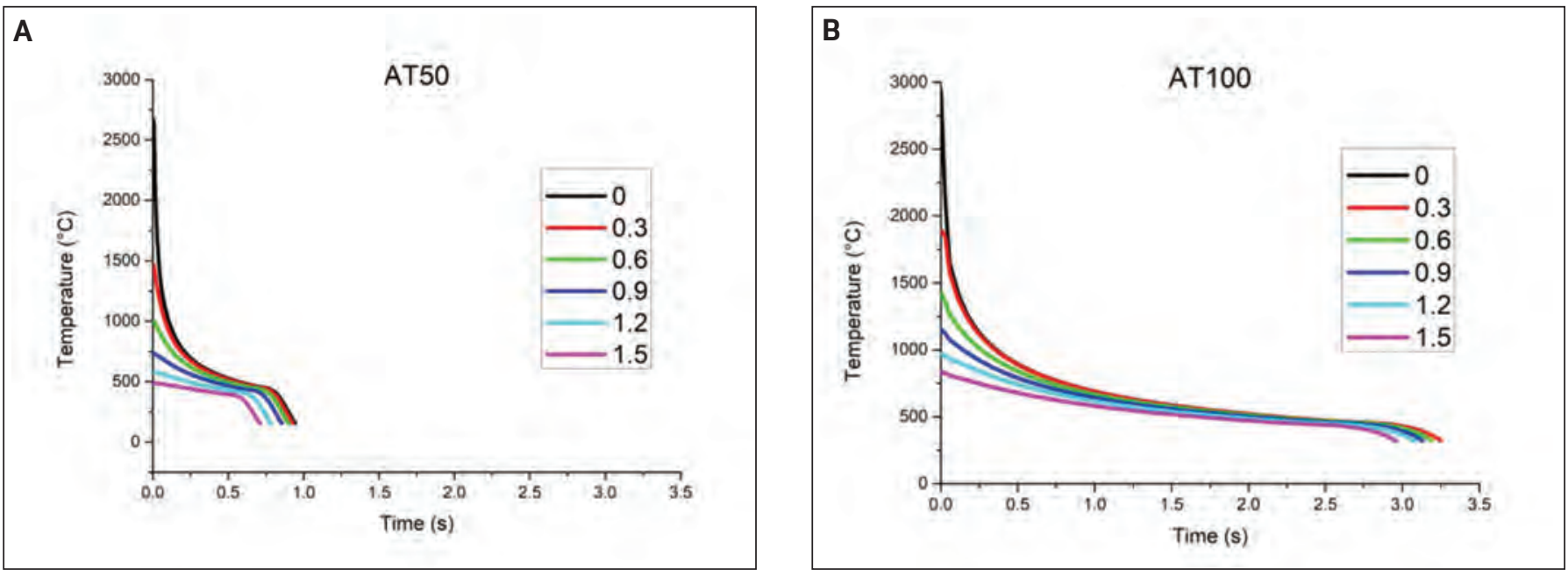

Fig. 7 - Cooling curves as a function of the position in relation to the center of the FZ obtained by SYSWELD software: A - AT50; B - ATIOO.

condition, and the average values, of each measured parameter, were taken for the result analyses. The fractured surfaces of the tensile test specimens were examined by a Vega 3 - Tescan SEM.

\section{Results}

\section{As-Received Microstructural Characterization}

The microstructural analysis of the as-received UNS S32304 DSS (Fig. 4) showed that the structure is lamellar with grains aligned in the rolling direction, composed of austenite islands in a ferritic matrix. The phase fraction measurements, using the quantitative metallography method, highlighted a microstructure constituted of $55 \pm$ $5 \%$ of ferrite and $45 \pm 5 \%$ of austenite.

The EBSD image of the as-received sample confirmed that the phases indicated as ferrite (darker phase) and austenite (lighter phase) analyzed by the OM was accurate, as shown in Fig. 5.

\section{Computational Simulation}

The characteristics of the weld bead, such as penetration depth, FZ width, and cooling rate in laser welding, are dependent on the speed and power of the process. Figure 6 shows the temperature distribution as a function of the po- sition relative to the center of the weld bead estimated by the SYSWELD software.

The yellow dots indicate the fixed points in relation to the center of the weld bead for which the temperature variation as a function of time was calculated during the laser passage. The mesh width is $0.3 \mathrm{~mm}$, as shown in Fig. 6 . The point in the center of the weld bead is the distance 0 , the second point indicates the distance of $0.3 \mathrm{~mm}$, and so on to the last point $(1.5 \mathrm{~mm})$. Figure 7 shows the result of the computational simulation obtained using the SYSWELD software. Time 0 represents the time at which the laser focus was on the FZ at the position 0 . In this way, the temporal evolution of the temperature at these fixed points after the passage of the laser can be observed. Figure 6 considers the melt bath above $1500^{\circ} \mathrm{C}$, while in Fig. 7 the temperature curves at point 0 extend to the vaporization limit.

According to the simulations done in the SYSWELD, the average cooling rate at the center of the weld (distance 0 ), from the maximum temperature to around $500^{\circ} \mathrm{C}$, in the AT50 sample was roughly $3870^{\circ} \mathrm{C} / \mathrm{s}$. The AT100 sample cooling rate was approximately $1105^{\circ} \mathrm{C} / \mathrm{s}$, about 3.5 times lower than the one calculated for the AT50, as may be observed in Fig. 7.

\section{Fusion Zone Characterization}

As shown in Fig. 6, the FZ and HAZ are smaller in the welded joint manufactured with a speed of $2400 \mathrm{~mm} / \mathrm{s}$ and a laser power of $2000 \mathrm{~W}$ (AT50) than in the one with a speed 

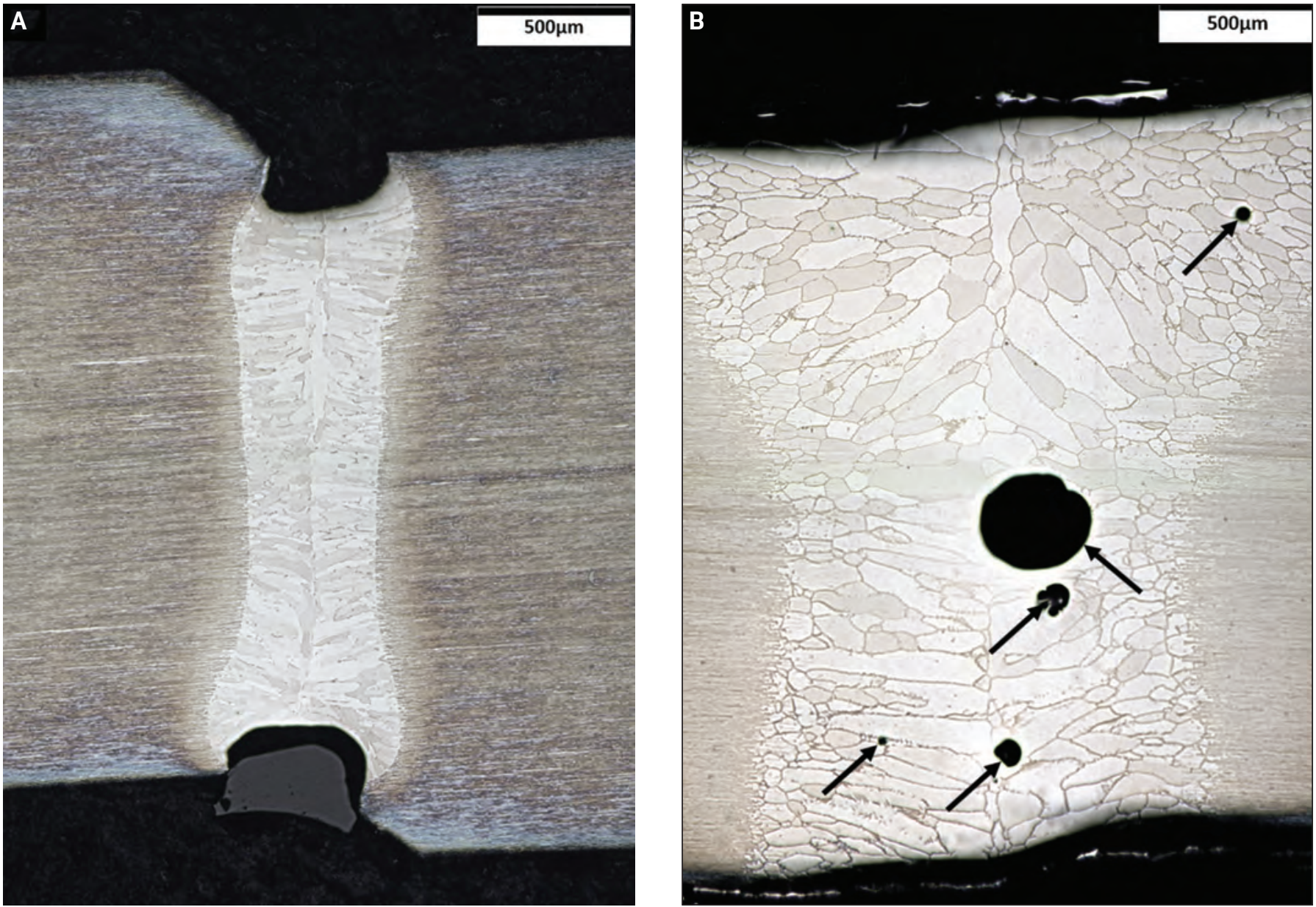

Fig. 8 - Micrographs of FZs: A - AT50; B - AT10O. $\mathrm{KOH}$ electrolytic etching. OM-50X.

of $600 \mathrm{~mm} / \mathrm{s}$ and a laser power of $1000 \mathrm{~W}$ (AT100). For the abovementioned welding conditions, a heat input of 50 and $100 \mathrm{~J} / \mathrm{mm}$ is generated, respectively.

Figure 8 shows the micrograph of the weld bead of plates that were welded applying the same simulating conditions. The welds exhibited a typical keyhole shape. Comparing the results presented in Figs. 6 and 8, it is possible to verify that the morphology of the weld beads is consistent with that predicted by the simulation. The width of the FZ in sample AT50 and AT100 was approximately 444 and $1376 \mu \mathrm{m}$ in the center of the weld bead, respectively. These values were similar to those calculated by the simulation; that is, 400 and $1000 \mu \mathrm{m}$, which validate the computational model. Figure $8 \mathrm{~B}$ shows the presence of porosity in the FZ. These porosities were observed recurrently in the laser-welded joints, some of which had a small fraction of pores (considered in this study as around $0.4 \pm 0.2$ $\mathrm{mm}^{-2}$ ) and other higher fractions (considered in this study as around $1.0 \pm 0.2 \mathrm{~mm}^{2}$ ).

The solidification process in the FZ involves epitaxial growth from the BM to the weld interface. The initial dendritic growth is oriented toward the direction of the thermal gradient and produces a columnar ferritic structure. From this structure, the other transformations in the solid state are obtained after the cooling (Ref. 1), as can be seen in Fig. 8. The initial lamellar structure, typically observed in DSSs, was replaced by elongated ferritic grains with columnar growth oriented in the direction of the heat flow, whereas the austenite concentrated in the ferrite grain boundaries in both welding conditions. The volume fraction of austenite in the samples AT50 and AT100 were 1.8 and 3.5\%, respectively, indicating that a small amount of austenite was reformed during the cooling stage, as shown in Fig. 9.

The electrolytic etching with oxalic acid evidenced the presence of chromium nitrides (Fig. 10), as well as in the work of Ramirez et al. (Ref. 9). The chromium nitrides precipitated in the ferrite grain boundaries in both samples. However, chromium nitrides were concentrated within ferrite grains in the AT100 sample, as observed in Fig. 10B.

For a further investigation, aiming to confirm the precipitation of chromium nitrides at some ferrite grain boundaries in the FZ, the AT50 sample was analyzed by SEM submitted to two different etchants: oxalic acid and Beraha II. The first one was adopted to indicate the indirect effect of sensitization, that is, chromium-depleted zones that are susceptible to preferential corrosion during the etching (Refs. 27, 31, 32). The second one was applied to reveal directly the chromium nitrides as a mean of confirmation. In both etchings, indirectly or directly, it was possible to obtain evidences of the chromium nitrides precipitation along the $\alpha / \alpha$ grain boundaries, as indicated in Fig. 11. It was not possible for the precipitation of $\mathrm{Cr}_{2} \mathrm{~N}$ within ferrite grains to be observed neither by $\mathrm{OM}$ nor SEM in the AT50 sample because of the limitation of the later- 

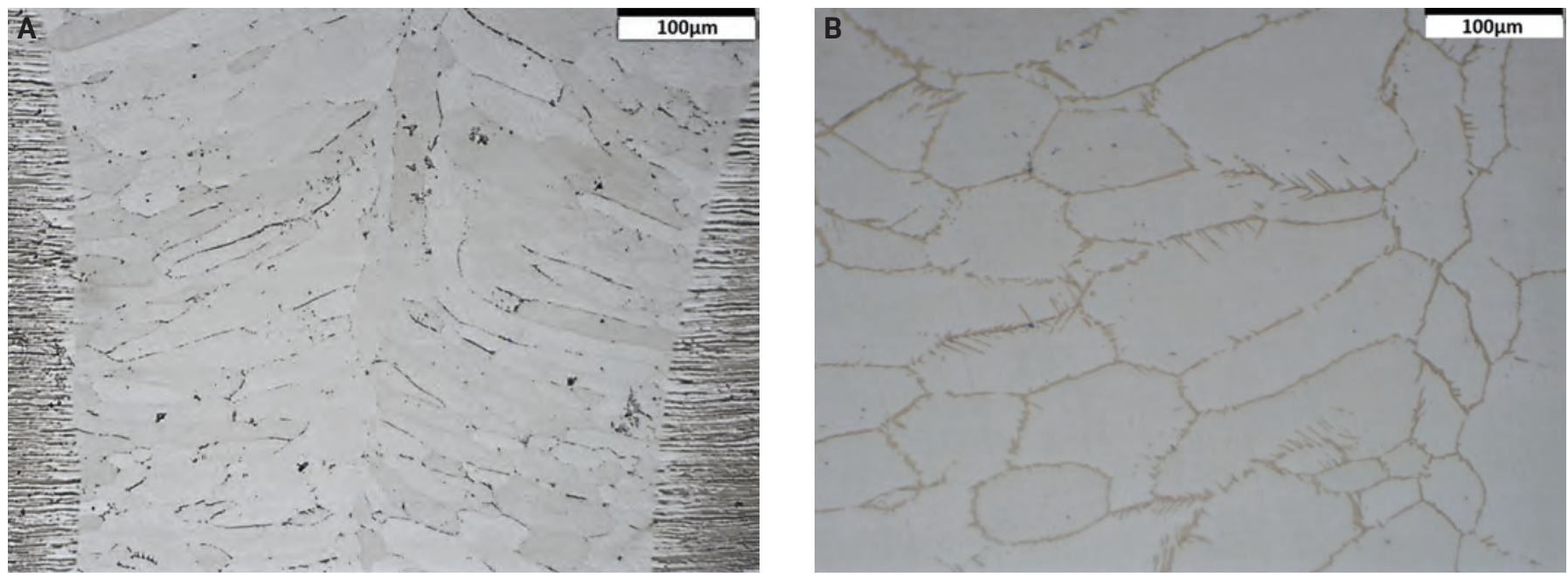

Fig. 9 - Detailed micrographs of FZs: A - AT50; B - AT100. KOH electrolytic etching. OM-200x.
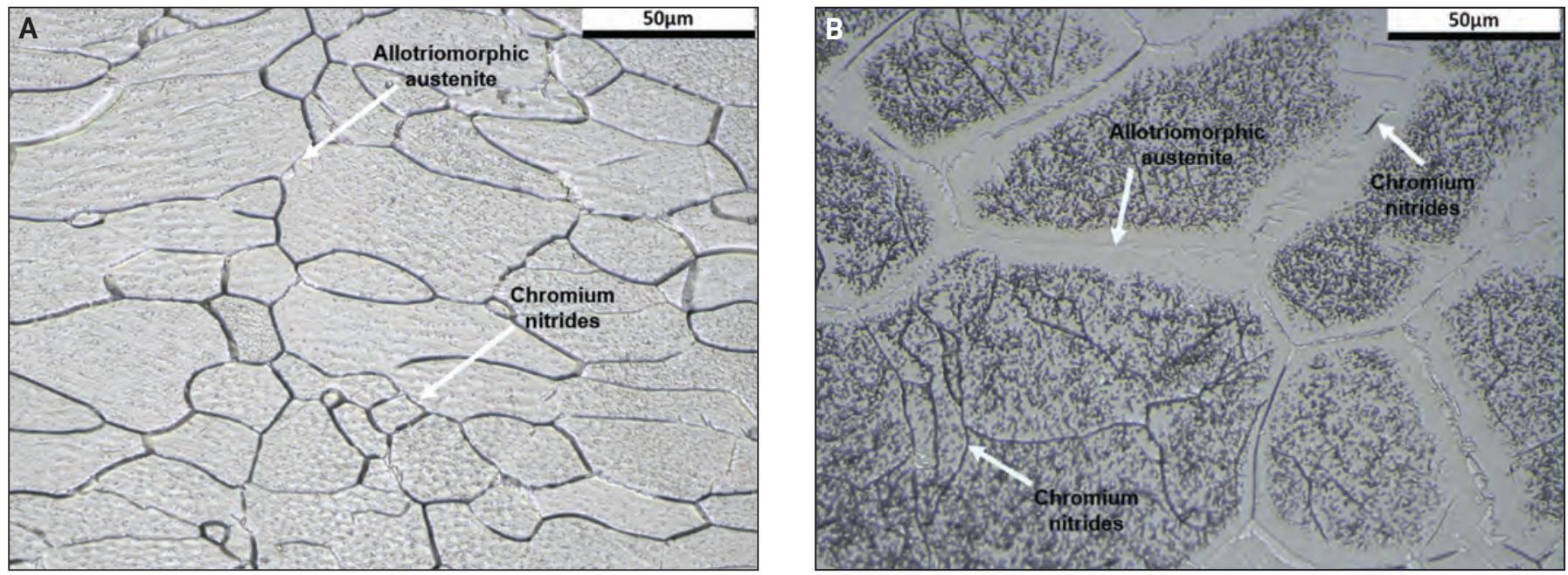

Fig. 10 - Micrographs of FZs (A) AT50 and (B) AT100, indicating the precipitation of chromium nitrides and austenite. KOH electrolytic etching followed by oxalic acid etching. OM-500x.

al resolution of these techniques.

Complementary analyses were performed in a TEM with the aim to confirm the presence of chromium nitrides within ferrite grains. The TEM analyses confirmed the presence of tiny needles precipitates in the AT100 sample, typical of chromium nitrides precipitated within ferrite grains (Fig. 12), as observed in a previous study by Yang et al. (Ref. 33). Due to the size of the TEM sample prepared in FIB, the tangle of lines in Fig. 10B could not be observed.

\section{Effects of PWHTs on the Microstructure}

The effects of laser PWHTs on the microstructure will be presented only for the AT100 condition, since this was the condition of greater representativeness because it presented the greatest amount of reformed austenite in the FZ just as welded and had fewer defects in the welded joint.

Heat treatments had a significant effect on the fraction and morphology of the austenite found in the FZ, as shown in Fig. 13A-D. In the sample heat treated at $850^{\circ} \mathrm{C}$, the microstructure consisted of a ferritic matrix with the reformed austenite concentrated mainly in the ferrite grain boundaries. Widmanstätten austenite formation was also observed, nucleating from the reformed austenite in the ferrite grain boundary - Fig. $13 \mathrm{~A}$. At $950^{\circ} \mathrm{C}$, there was a significant increase in the amount of intragranular austenite and in the nucleation and growth rate of Widmanstätten austenite from the reformed austenite in the ferrite grain boundary - Fig. 13B. An increase in the amount of Widmanstätten austenite was noticed, as well as the presence of intragranular austenite at $1050^{\circ} \mathrm{C}-$ Fig. $13 \mathrm{C}$. In the isothermal heat treatment at $1150^{\circ} \mathrm{C}$, a refined structure with the predominance of intragranular austenite and the spheroidization of some austenite particles were observed - Fig. 13D.

Table 3 shows the volumetric fraction of austenite/ferrite phases for the different heat treatment temperatures. Notice when increasing temperature from $850^{\circ}$ to $1150^{\circ} \mathrm{C}$, the austenite fraction also increased. It is important to emphasize only the volumetric fraction of austenite/ferrite phase was evaluated in this work. The PWHT did not have the aim to reach the thermodynamic equilibrium condition, or to reestablish the prior weld phase chemical composition, but 

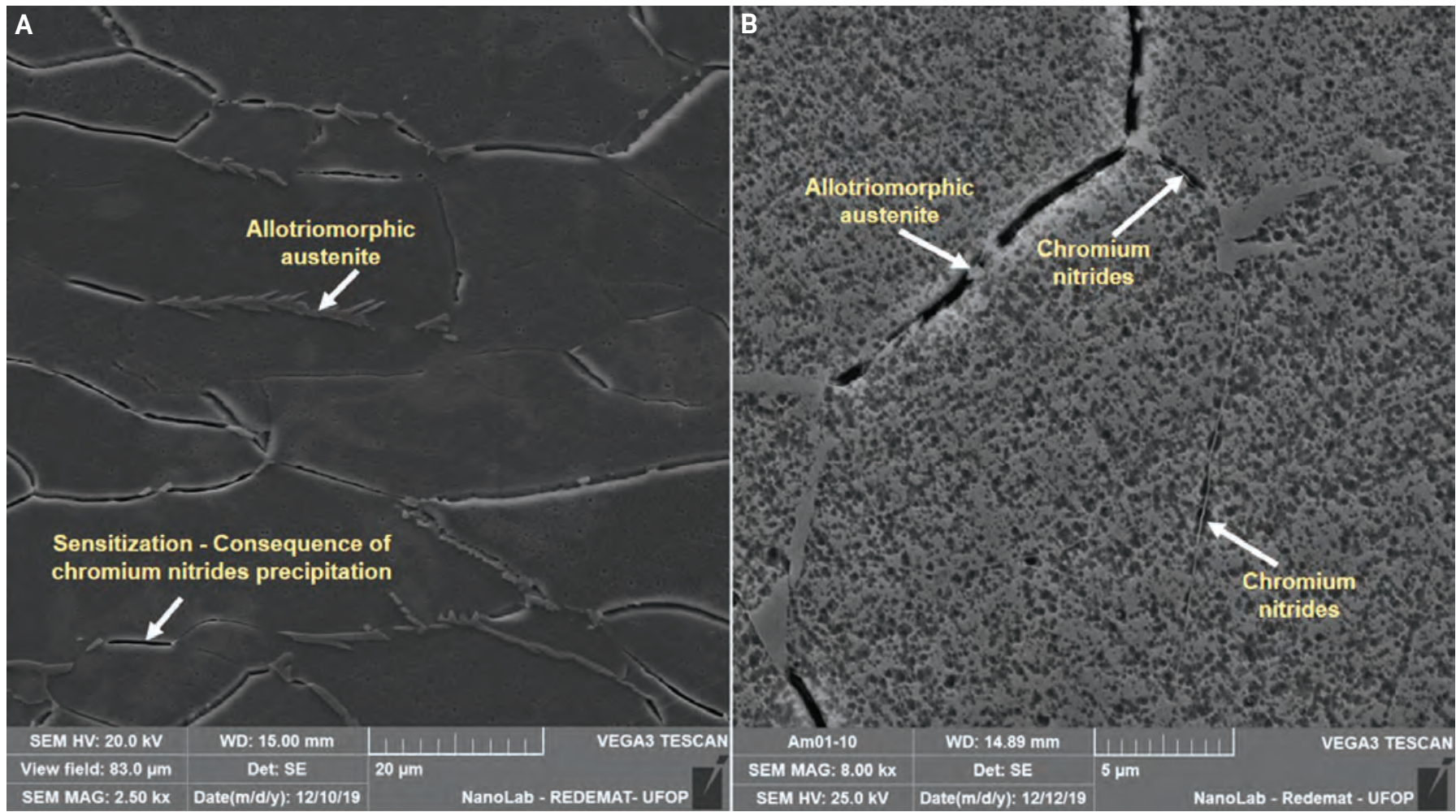

Fig. 11 - SEM micrographs of FZ of AT50 sample: A - Oxalic acid; B - Beraha II etchings.

Table 3 - Volume Fractions of Austenite and Ferrite at Different Heat Treatment Temperatures

\begin{tabular}{ccc} 
Sample & \% Austenite & \% Ferrite \\
\hline L1 & 18,7 & 81,3 \\
L2 & 37,0 & 63,0 \\
L3 & 38,0 & 62,0 \\
L4 & 44,2 & 55,8 \\
\hline
\end{tabular}

just to readjust the phase fraction balance and dissolve deleterious precipitates in a relatively short time that makes its use economically and operationally feasible (Ref. 24). Due to that, the chemical composition in the weld was not estimated, but according to the literature, it is possible to affirm that the ferrite phase is richer in $\mathrm{Cr}$ and Mo while the austenite is richer in $\mathrm{Ni}$ and $\mathrm{N}$ during the short-time PWHT (Ref. 34).

It is well known that nitrogen plays an important role in the austenite formation in the FZ during cooling of DSS. In welding processes, there is a tendency of nitrogen loss, and it can affect the amount of austenite precipitated in the weld metal. According to the literature (Ref. 35), nitrogen depletion in the FZ of DSS welds is most seriously observed in gas tungsten arc welding. In laser welding, the nitrogen depletion in the FZ occurs in a smaller magnitude when compared to other welding processes. Due to the complexity of the characterization techniques to perform an accurate measurement of nitrogen in such a narrow region as in the FZ of laser welding, the nitrogen amount was not measured in this work, but in the scientific literature, there are some studies showing the loss of nitrogen in the weld pool. For example, Lai et al. (Ref. 36) measured the nitrogen content in the weld pool by the oxygen and nitrogen analyzer, LECO TC-436 in a 2205 DSS fiber laser welded with $100 \%$ Ar as a shielding gas. The percentage of nitrogen in the as-received sample was $0.16 \mathrm{wt}-\%$, while the amount of nitrogen in the weld pool was 0.085 wt-\% in the center section of the weld and $0.095 \mathrm{wt}-\%$ in the upper section of the weld. According to them, the decrease of nitrogen content can lead to dropping the amount of austenite reformed in the FZ during the FZ cooling.

As shown in Fig. 14, in addition to the readjustment of the austenite fraction, the L4 sample had the chromium nitride fraction considerably decreased, and it was not possible to observe this via the OM.

The EBSD images of the FZ of the samples AT100 and L4 (Fig. 15) present the evolution of austenite growth, from the as-welded condition to PWHT at $1150^{\circ} \mathrm{C}$ for $10 \mathrm{~min}$. Thus, the higher amount of reformed austenite among the temperatures of the heat treatments evaluated was obtained.

The EBSD phase quantification analysis of AT100 and L4 samples was 96.2 and $61.2 \%$ of ferrite and 1.8 and $27.8 \%$ of austenite, respectively. The fraction of points that were not indexed in the EBSD analysis was presented as zero solu- 

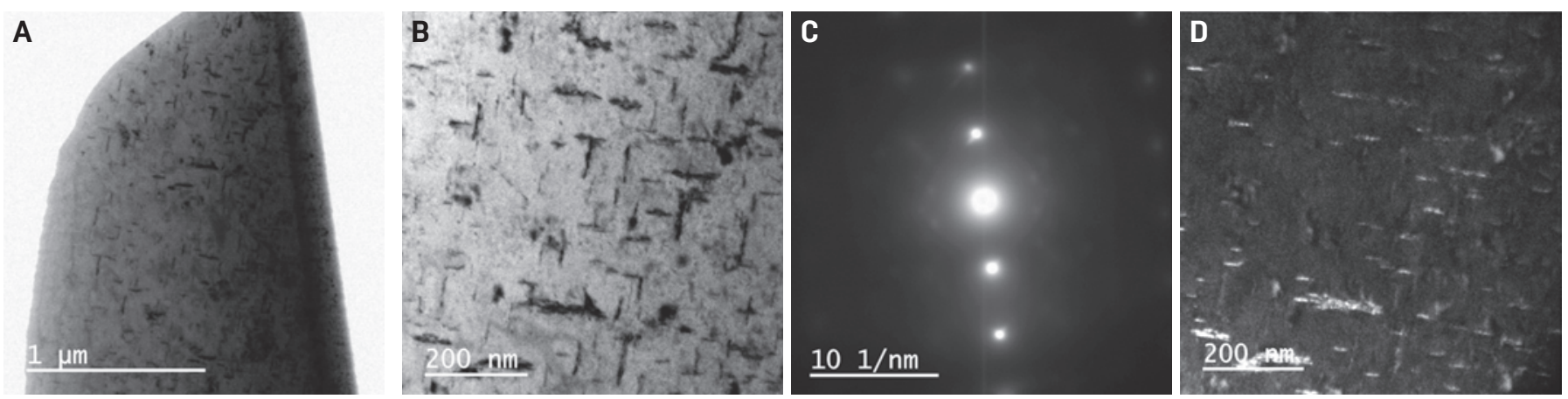

Fig. 12 - TEM analyses of AT100 sample: A - TEM micrograph; B - TEM micrograph showing in detail the chromium nitrides as a needle morphology; $\mathrm{C}$ - diffraction profile of ferritic matrix coincident with $\mathrm{Cr}_{2} \mathrm{~N} ; \mathrm{D}$ - elastic scattering image correspondent to $\mathrm{C}$

Table 4 - Vickers Microhardness and Volume Fraction of Austenite in the Fusion Zone

\begin{tabular}{cccc} 
& BM & FZ & \% Austenite (FZ) \\
\hline AT50 & $263 \pm 4$ & $319 \pm 8$ & 1,8 \\
AT100 & $250 \pm 8$ & $272 \pm 5$ & 3,5 \\
L1 & $235 \pm 4$ & $219 \pm 7$ & 18,7 \\
L2 & $237 \pm 5$ & $234 \pm 7$ & 37,0 \\
L3 & $240 \pm 5$ & $237 \pm 8$ & 38,0 \\
L4 & $232 \pm 8$ & $238 \pm 8$ & 44,2 \\
\hline
\end{tabular}

tions: 2.0 and $11.0 \%$ for each sample. It should be highlighted that in the EBSD analysis, the indexing routine is a challenge for accurate data (Ref. 37). Taking this into consideration, and also that phase measurement by the OM for DSS is a consolidated technique in the literature (Refs. 21, 22, 25), the discussion of the results was made considering the phase amounts obtained via OM analysis. Hosseini et al. (Ref. 26) stated the most accurate method to measure the phase amounts of DSS welds was the etching with modified Beraha followed by image analysis software.

\section{Vickers Microhardness and Ultramicrohardness}

The results obtained from the microhardness tests are presented in Table 4. The samples AT50 and AT100 had the highest hardness values in the FZ, $319 \pm 8$ and $272 \pm 5$ $\mathrm{HV}$, respectively.

The ultramicrohardness of the specific phases (ferrite and austenite) were evaluated only for the extreme conditions (AT100 and L4), shown in Table 5. Because of the AT100 condition, the microstructure is mostly ferritic; as a result, the hardness measurement of austenite was not performed. Instead of the ferrite hardness, the measured microhardness for the FZ was applied. The theory guarantees the load of the hardness test on the Vickers scale does not significantly change the hardness values.

\section{Corrosion Tests}

Samples AT100 and L4 were subjected to a corrosion test with microarea analysis to examine the effects of welding

\begin{tabular}{lcccc}
\hline \multicolumn{2}{c}{ Table 5 - Vickers Hardness } & & \\
\multicolumn{1}{c}{ BM } & \multicolumn{2}{c}{ FZ } \\
\hline Austenite & Ferrite & Austenite & Ferrite \\
AT100 & $339 \pm 10$ & $264 \pm 16$ & $* \star *$ & $272 \pm 5$ \\
L4 & $298 \pm 9$ & $267 \pm 10$ & $304 \pm 7$ & $268 \pm 5$ \\
\hline
\end{tabular}

and PWHTs on the corrosion resistance of the FZ and BM. These conditions were chosen based on the results obtained by the microscopic analysis related to the weld quality and the austenite/ferrite adequate ratio. Figure 16 shows the $\mathrm{BM}$ and FZ polarization curves for each condition.

In the as-welded sample (AT100), there was a marked decrease in the corrosion resistance for the $\mathrm{FZ}$ in relation to the BM, whereupon the BM of the AT100 sample had a behavior that was similar to the as-received material. The values of $\mathrm{E}_{\text {corr }}$ (corrosion potential) and $\mathrm{j}_{\text {corr }}$ (corrosion current density), listed in Table 6, show that the BM had a more noble potential than the FZ under this condition (AT100).

Although the analysis indicated a pitting potential near $0.9 \mathrm{~V}$, in the FZ of the postweld heat treated sample (L4), the pits did not become stable in the studied potential range up to $1 \mathrm{~V}$. As both samples had low and very close corrosion current values, of the order of $10^{-7} \mathrm{~A} \cdot \mathrm{cm}^{-2}$, it is possible to affirm the heat treatment did not significantly affect the corrosion current density of the samples.

\section{Tensile Tests}

The stress-strain curves for as-received, laser-welded (AT100), and postweld heat-treated (L4) samples are shown in Fig. 17. The tests were conducted for condition L4, considering two specimen groups classified in function of their porosity: one with a relatively low fraction of pores $(0.4 \pm 0.2$ $\left.\mathrm{mm}^{-2}\right)$ and another with a relatively high fraction (1.0 \pm 0.2 $\mathrm{mm}^{-2}$ ). As the porosity of the weld bead was recurrent, considering the laser welding condition applied to the studied DSS, this was done to evaluate the effect of the pore fraction on the tensile behavior of the postweld heat-treated samples.

Table 7 shows the parameters measured in the tensile test. From the first analyses, it can be seen that the as-received specimen presented the highest yield strength (578 MPa), followed by the AT100 condition, L4 with higher porosity on the fractured surface (Fig. 18A), and L4 with lower porosity 

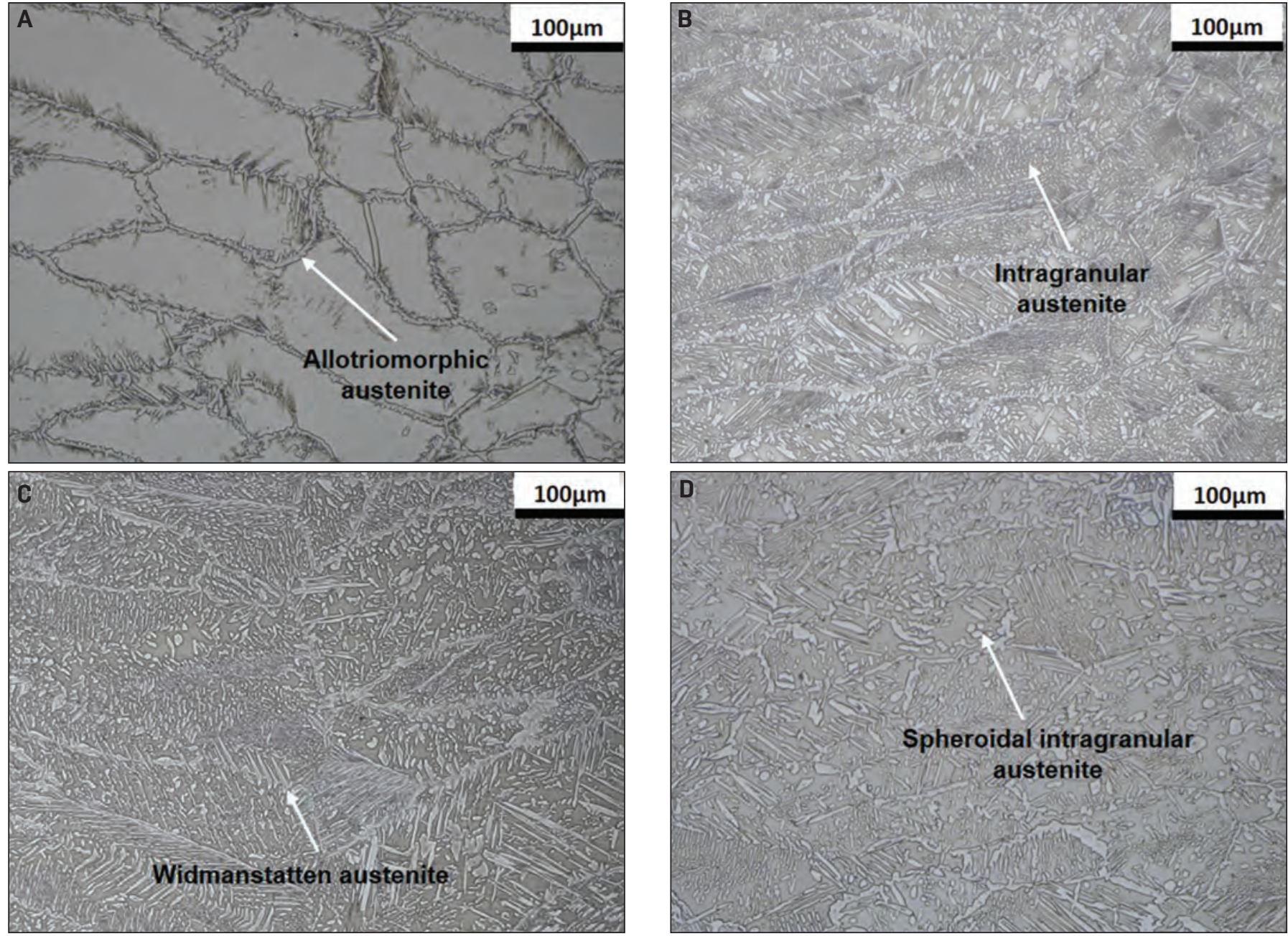

Fig. 13 - Micrograph of the FZ after isothermal heat treatment at different temperatures for 10 min: $A-850^{\circ} \mathrm{C} ; \mathrm{B}-950^{\circ} \mathrm{C} ; \mathrm{C}-$ $1050^{\circ} \mathrm{C} ; \mathrm{D}-1150^{\circ} \mathrm{C}$. $\mathrm{KOH}$ electrolytic etching. OM-200x.

- Fig. 18B. Comparing the ultimate strength of the samples, the as-received specimen had the highest value (729 $\mathrm{MPa}$ ), followed by the AT100 condition, L4 with lower porosity, and L4 with higher porosity (605 MPa). The as-received and AT100 conditions had higher tensile strength than the heat-treated samples of both groups. Also, the asreceived specimen was the one that deformed the most (52\%), presenting greater ductility. Then, the specimen, postweld heat treated at $1150^{\circ} \mathrm{C}$ and with lower porosity exhibited a greater plastic elongation (30\%). While as-welded and L4 with higher porosity were the least plastic deformed, both presented a total deformation of $22 \%$. In all specimens, the fracture occurred in the weld bead.
The as-received sample had a completely ductile fracture surface (Fig. 19A), while the as-welded specimen revealed a semiductile fracture. The fractured surface of this sample was subjected to electrolytic etching with oxalic

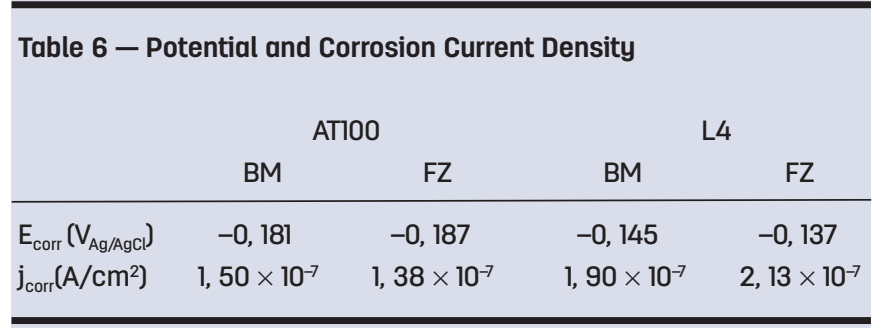

Table 7 - Vield Strength $\left(\sigma_{y S}\right)$, Ultimate Strength $\left(\sigma_{\text {ult }}\right)$, Total Strain $\left(\varepsilon_{\tau}\right)$, and Reduction Area (R.A.) of the Tensile Test Specimens Evaluated

$$
\text { Condition }
$$

As-received

AT100

L4 (higher porosity)

L4 (lower porosity)
$\sigma_{\mathrm{ys}}(\mathrm{MPa})$

578

485

462

426
$\sigma_{\mathrm{ult}}(\mathrm{MPa})$

\section{9}

675

605

666 $\varepsilon_{\tau}(\%)$

R.A. (\%)

50
29
30
37



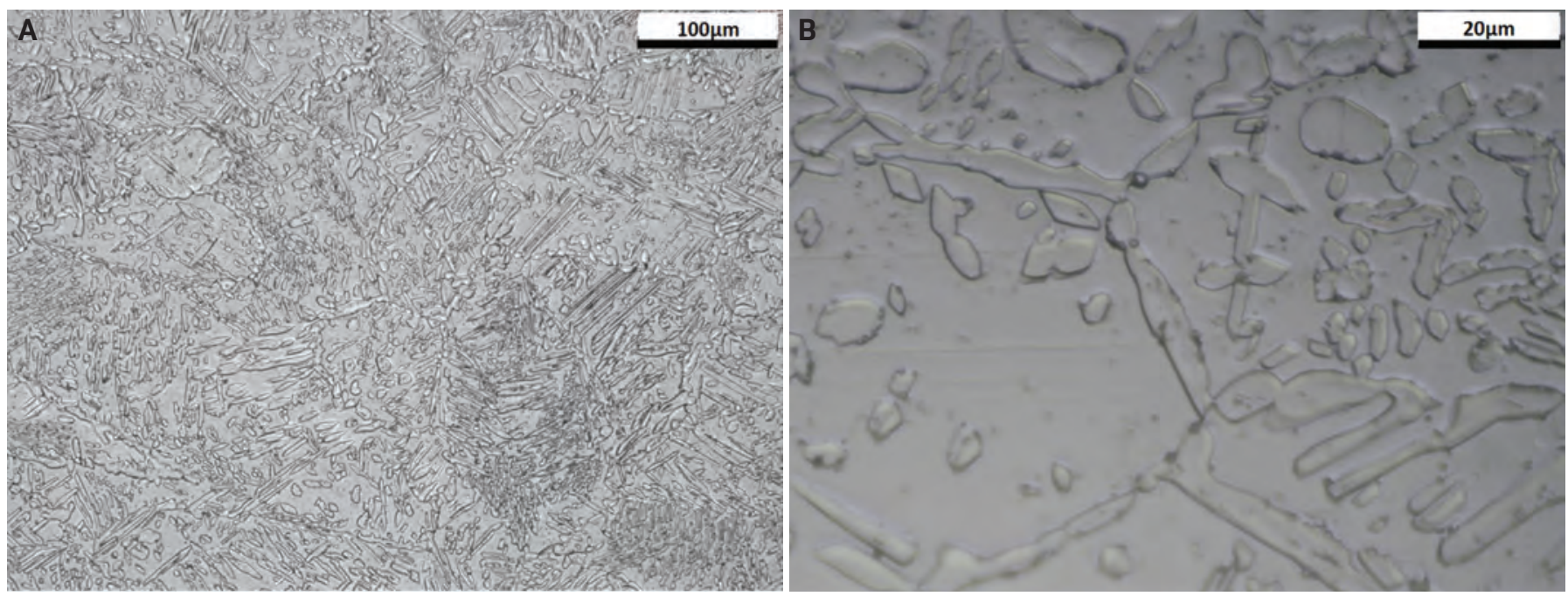

Fig. 14 - Micrographs of FZ of L4 sample indicating the dissolution of chromium nitrides: A - OM-200X; B - OM-1000x. KOH electrolytic etching followed by oxalic acid etching.
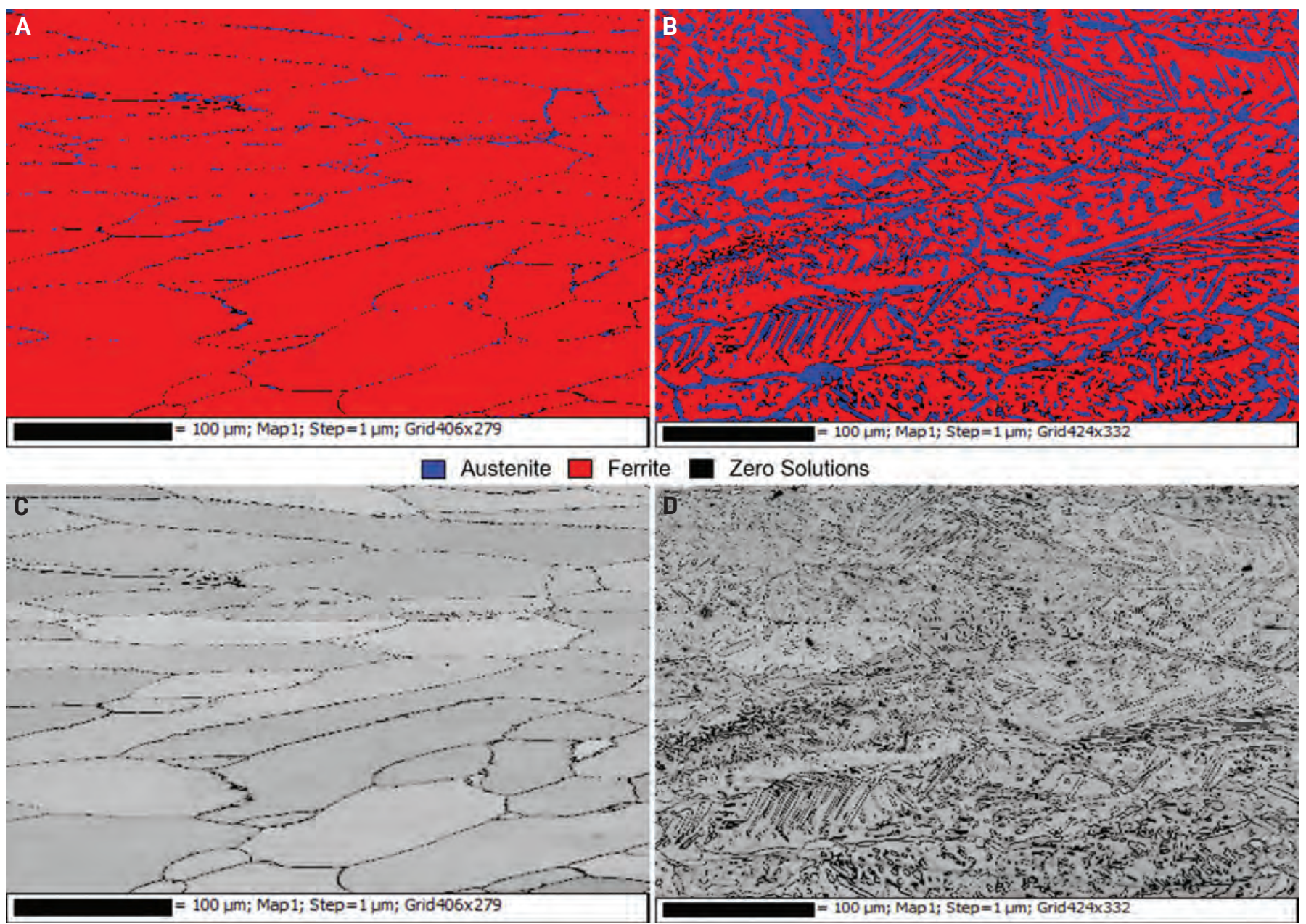

Fig. 15 - EBSD maps: FZ phase distribution of the samples: A - AT700; B - L4. Band contrast: C - AT100; D - L4.

acid, so the presence of chromium nitrides inside the cleavage facets was revealed - Fig. 19B. The heat-treated specimens presented a semiductile fracture, and the sam- ple with the highest porosity presented a smaller extent of ductile fracture (presence of dimples) (Fig. 20A) than the one with lower porosity in the FZ - Fig. 20B. 


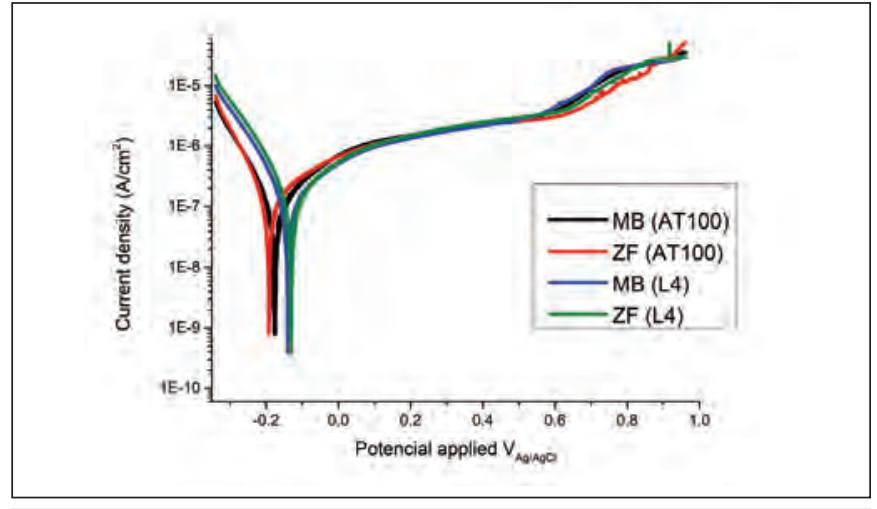

Fig. $16-B M$ and FZ polarization curves of samples AT100 and L4, set up by a potentiostatic test performed in an aerated aqueous solution with a nitrogen flow in $3.5 \mathrm{wt}-\% \mathrm{NaCl}$ at room temperature.

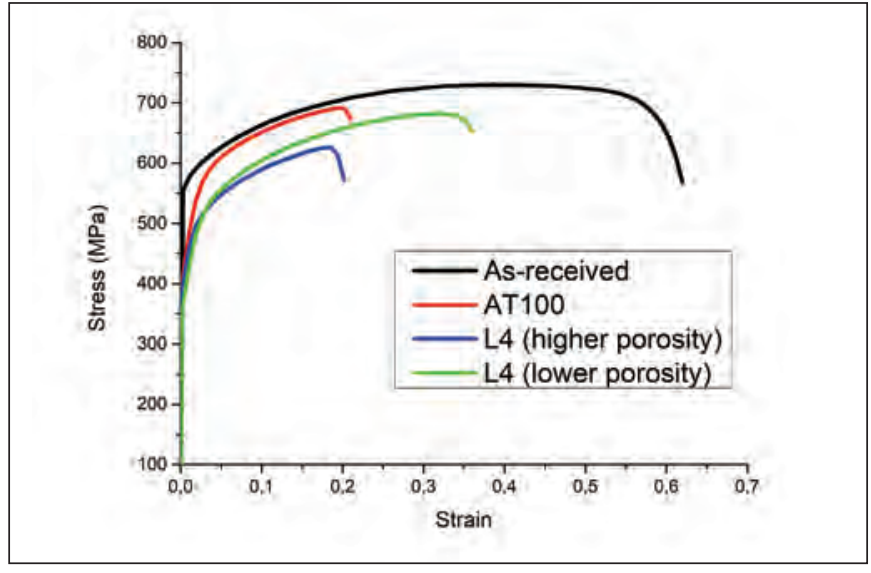

Fig. 17 - Stress-strain curves obtained in the tensile tests for different conditions.
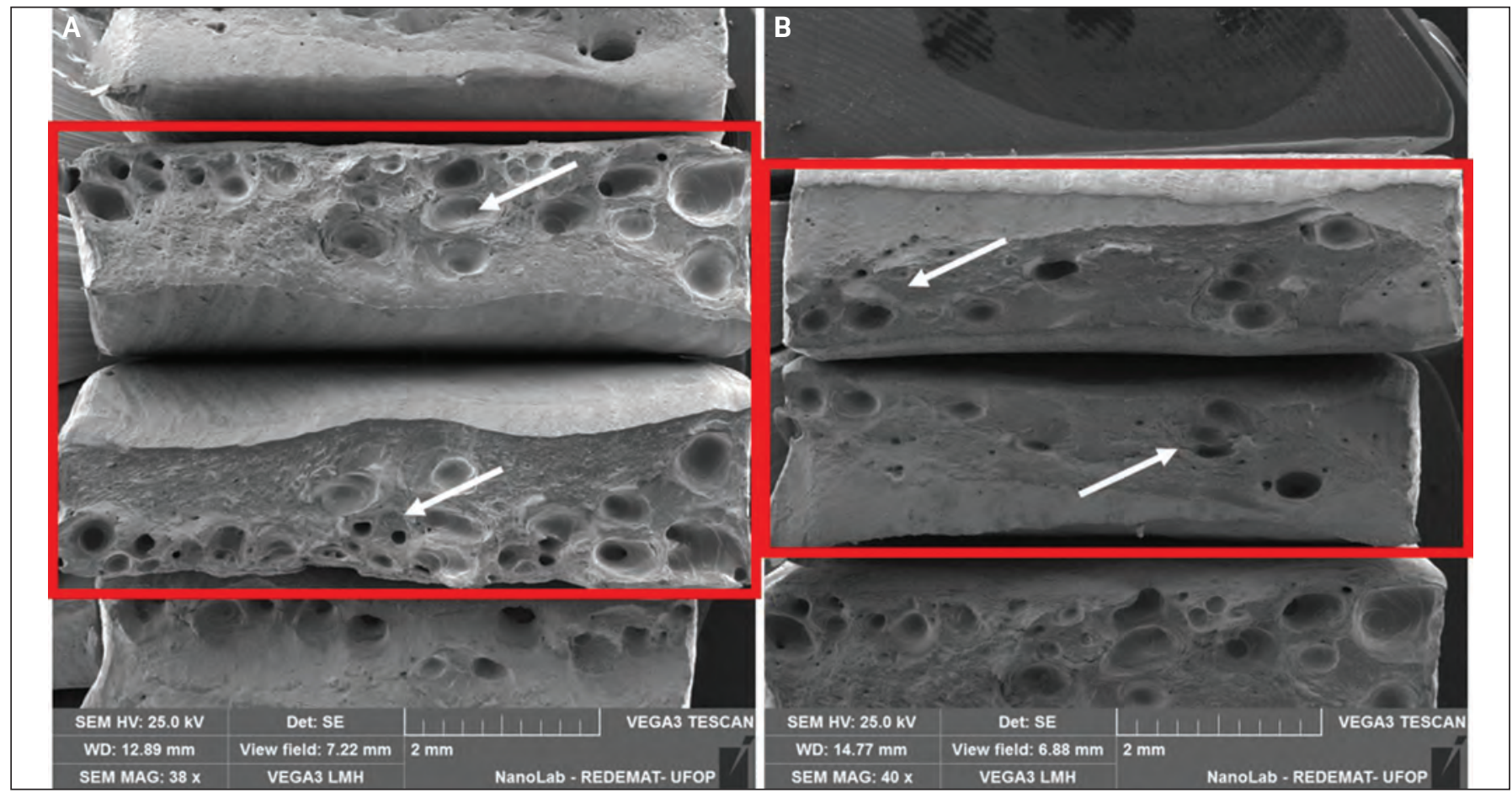

Fig. 18 - SEM surface images of tensile test specimens heat treated at $1150^{\circ} \mathrm{C}$, indicating the presence of pores (white arrows): A - High porosity; B - low porosity.

\section{Discussion}

\section{Simulation and Laser Welding}

Under both welding conditions, the FZ reached a temperature above $1500^{\circ} \mathrm{C}$. Ramirez et al. (Ref. 9) found that at $1350^{\circ} \mathrm{C}$, there is a complete dissolution of austenite in UNS S32304 DSS, and the FZ becomes completely ferritic in the solidification. The austenite is reformed only during the welded joint cooling to room temperature, if there is enough time for the diffusional processes to occur. It was also noticed that the cooling rate was higher in the first welding condition (AT50) than in the second (AT100), as presented in Fig. 7. Induced by laser welding, the high cooling rates cause the formation of an almost completely ferritic structure in the FZ after cooling (Ref. 8). If the cooling is fast, the time is insufficient for austenite nucleation and growth. The cooling rate is fundamental to the extent of the transformation (Ref. 1). The austenite precipitation is a nucleation and growth process controlled by diffusion. The reformed austenite is controlled by a paraequilibrium transformation mechanism, whereby the diffusion of the interstitial elements (carbon and nitrogen) is the process controller (Refs. 1, 38). Thus, increasing the cooling rate will reduce the diffusion of austenite stabilizing elements, such as $\mathrm{N}$ and $\mathrm{Ni}$, and few austenite will be transformed from supersaturated ferrite (Ref. 39).

The heat input is an effective parameter to judge the quality of the weld surface and the properties of the welded material (Ref. 40). According to Zhao et al. (Ref. 41), the lower the 

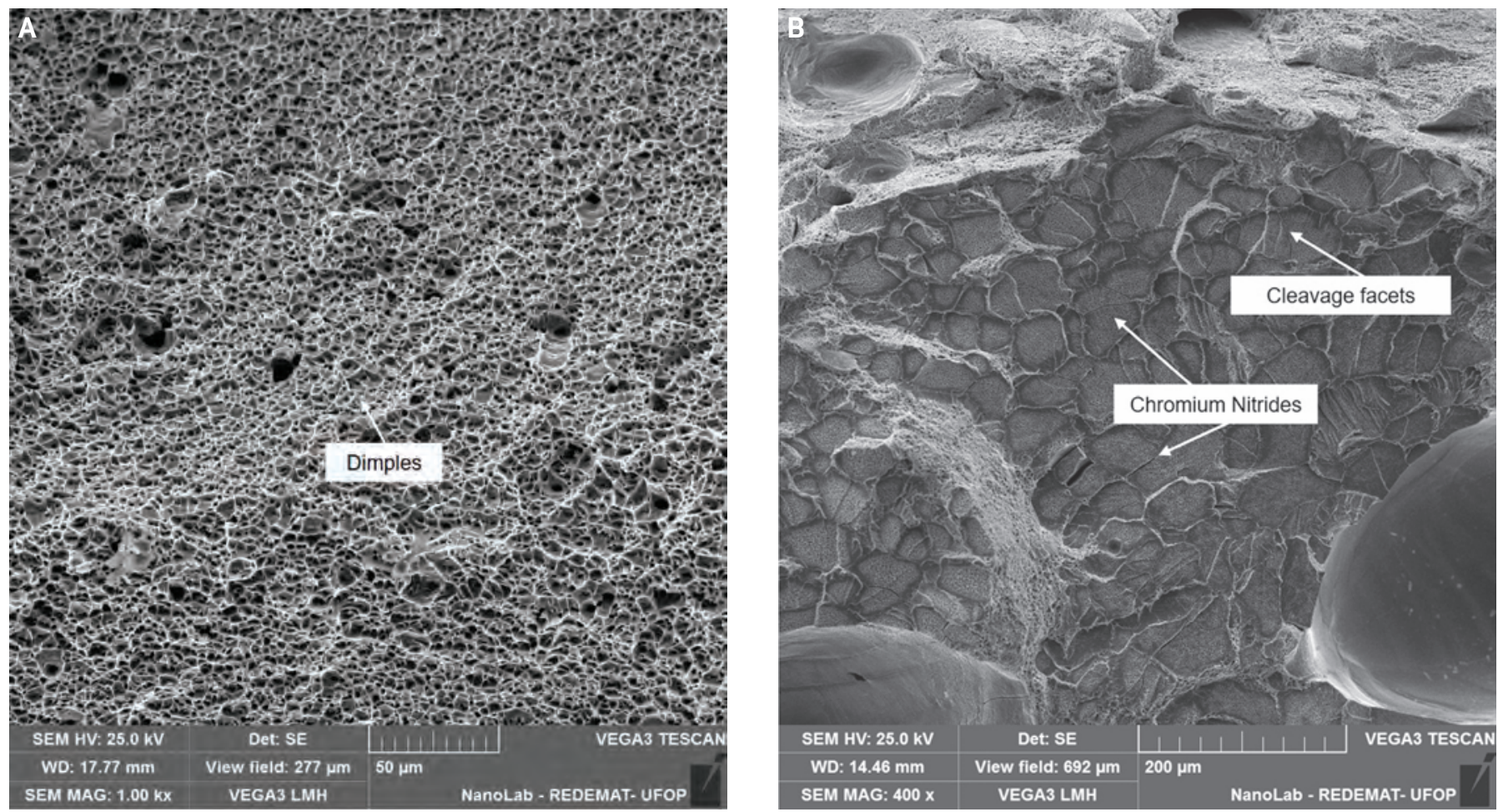

Fig. 19 - Fractography (A) as-received and (B) AT1OO indicating the presence of chromium nitrides. $\mathrm{KOH}$ electrolytic etching followed by oxalic acid etching, applying $3 \mathrm{~V}$ for $30 \mathrm{~s}$.

heat input, the lower the weld bead width because a smaller amount of material is molten. Therefore, the weld bead is narrower, as shown in Fig. 8 and in the computer simulation Fig. 6. The following is another important consideration: The lower the heat input, the higher the cooling rate, and hence, the lower the amount of reformed austenite during the welded joint cooling.

Regarding the as-received condition, besides the intense modification in the austenite and ferrite volume fractions, there may also be intense chromium nitride precipitation due to the rapid supersaturation of nitrogen in the ferrite during the fast cooling (Ref. 42).

According to Perren et al. (Ref. 43), $\mathrm{Cr}_{2} \mathrm{~N}$ is rarely found close to the ferrite/austenite grain boundaries because, during the quenching, the nitrogen that is close to the $\alpha / \gamma$ interface migrates to the adjacent austenite, which has a higher solubility by nitrogen than ferrite. In Fig. 11A, where there is secondary austenite along the grain boundaries, no preferential corrosion areas could be observed after the oxalic acid etching. This is because the nitrogen probably dissolved in austenite and the $\mathrm{Cr}_{2} \mathrm{~N}$ did not precipitate along the $\gamma / \alpha$ grain boundaries. Otherwise, where there is a preferential corrosion at $\alpha / \alpha$ grain boundaries, i.e., sensitization occurrence, it is possible to affirm it is an indirect indication of chromium nitride precipitation at the grain boundaries, responsible for chromium-depleted regions (Refs. 27, 28, 31, 32). Because the cooling rate in the AT50 sample is higher than in the AT100 sample, and a small amount of austenite had been reformed, the chromium nitrides were mainly concentrated in the ferrite grain boundaries - Fig. 10A. Bettini et al. (Ref. 44) also detected the presence of chromium nitrides along the $\alpha / \alpha$ boundaries. No chromium nitrides pre- cipitates were observed in the austenite phase as well, which is in accordance with this work - Fig. 11.

Magalhães et al. (Ref. 45) observed in a UNS S32304 DSS with a completely ferritic structure and fast cooled that there was precipitation of chromium nitrides in the form of black needles in the ferrite grains, similar to that verified in this study for the AT100 condition, as shown in Fig. 10B. The supersaturation of nitrogen in ferrite and the alignment of discordances favor the formation of chromium nitrides in subgrain boundaries, exhibiting this structure in the form of a tangle of lines (Refs. 22, 39, 43).

The suppression of austenite transformation in a high cooling rate condition propitiates a scenario that is favorable for obtaining a microstructure constituted of a high fraction of ferrite and chromium nitrides, which can result in the degradation of corrosion and mechanical properties of a welded joint (Ref. 9), as will be presented later.

Additionally, the presence of porosity found in the solidification of laser-welded joints are consistent with other studies (Refs. 46-51). Previous articles affirm that the porosity formation in laser welding will occur, if the solidification rate of the molten metal exceeds the backfilling speed of the liquid-metal during the keyhole collapse and solidification processes. Porosity formation is even more serious in laser welding, mainly because of the high cooling rates, as shown in the computational simulation. The porosity may cause damage to the quality of the weld, deteriorating its mechanical properties (Ref. 52).

\section{Effects of PWHT on the Microstructure}

Two types of secondary austenite $\left(\gamma_{2}\right)$ can be observed in 

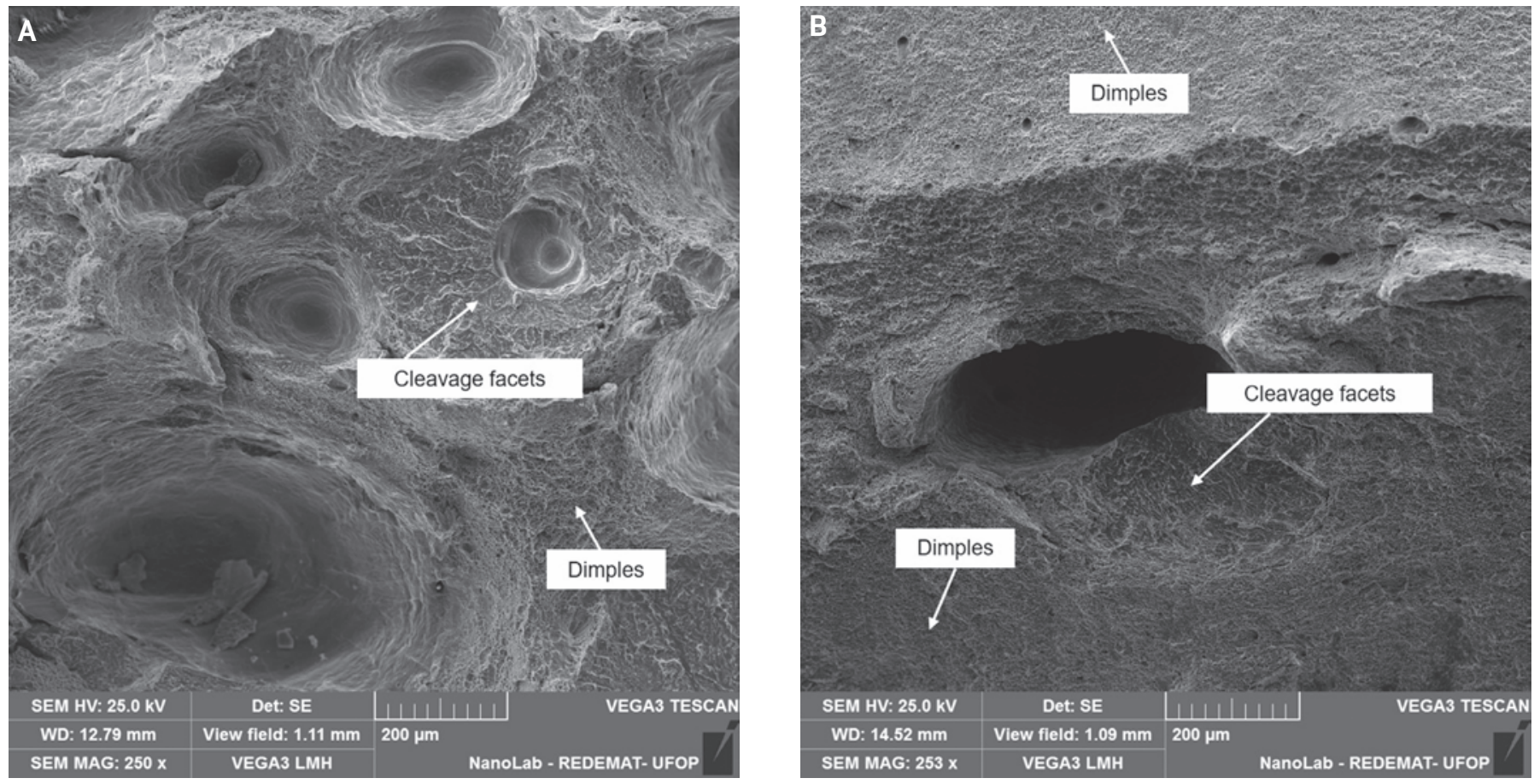

Fig. 20 - Fractography of L4 sample: A - High porosity; B - low porosity in the FZ.

DSSs based on their morphology and site of precipitation criteria. The first type is formed at the $\alpha / \gamma$ interfaces, denominated intergranular austenite. It is a result of the growth from the preexisting austenite particle toward the ferrite. The second type is intragranular $\gamma_{2}$, which nucleates and grows intragranularly in the ferrite (Refs. 9, 53). Within these two types, there are subclassifications of the morphology of $\gamma_{2}$, which are observed in Fig. 13 as the following: A) allotriomorphic along the ferrite grain boundaries, B) Widmanstätten, and C) intragranular austenite. Intragranular austenite particles assume a spheroid shape because they do not have a preferential orientation during their growth (Ref. 54). Zhang et al. (Ref. 53) reported the increase of the heat treatment temperature from $1020^{\circ}$ to $1050^{\circ} \mathrm{C}$ promoted the growth of austenite, the formation of intragranular austenite, and the complete dissolution of chromium nitrides. When the temperature increased from $1080^{\circ}$ to $1100^{\circ} \mathrm{C}$, the intragranular austenite particles were spheroidized, and the amount of secondary austenite decreased due to more rapid diffusion, and thus, it is in accordance with the present study.

Magalhães et al. (Ref. 45) used the Thermo-Calc software to simulate under thermodynamic equilibrium conditions and the austenite/ferrite fraction ratio as a function of the temperature for the UNS S32304 DSS. For this particular steel, at temperatures above $1250^{\circ} \mathrm{C}$, a completely ferritic microstructure can be obtained (during the laser welding process, temperatures reach around $1500^{\circ} \mathrm{C}$ at the fusion zone), and at temperatures around $800^{\circ}$ or $1050^{\circ} \mathrm{C}$, the $50 \%$ fraction for each phase is obtained. However, the sample that had the austenite fraction closest to $50 \%$ was the one submitted to $1150^{\circ} \mathrm{C}$ for $10 \mathrm{~min}$, approximately $44 \%$ (the value close to the amount of austenite in the as-received condition). This proportion in a relatively short time and at a temperature higher than that predicted by Magalhães et al. (Ref. 45) can be ex- plained by the fact that the simulation was done at equilibrium, and kinetic aspects were not considered.

In equilibrium phase diagrams, at temperatures around $1150^{\circ} \mathrm{C}$, there is a tendency for ferrite formation. However, the microstructure of the laser-welded FZ is almost completely ferritic as the cooling is extremely fast and there is not enough time for austenite precipitation during cooling. Thus, there is a driving force for the formation of austenite if the material is reheated, as this is a nonequilibrium condition. Therefore, if the laser-welded plate is heated at any temperature in the range studied in this paper, there will be a predisposition for austenite to be precipitated because they are postweld heat treated for a short time. It was noticed the higher the temperature, the kinetics of austenite formation was favored for this DSS. Therefore, the temperature of $1150^{\circ} \mathrm{C}$ was more suitable for the phase fraction readjustment in the fusion zone. Thus, it is important to emphasize the optimum heat treatment temperature is a variable, and it depends on the chemical composition of the steel and microstructural condition of the FZ. Austenite formation is a time-dependent diffusional process. According to Magalhães et al. (Ref. 45), the residence time at the treatment temperature proved to be a parameter of great influence on the transformation of ferrite into austenite.

Moreover, the dissolution of $\mathrm{Cr}_{2} \mathrm{~N}$ at $1150^{\circ} \mathrm{C}$ PWHT can be attributed to a cooperative mechanism of precipitation of intergranular nitrides and $\gamma_{2}$, as explained by Ramirez et al. (Ref. 9). The precipitation of $\mathrm{Cr}_{2} \mathrm{~N}$ at $\alpha / \gamma_{\text {primary }}$ precedes the growth of the secondary austenite. The low-energy interfaces formed between $\mathrm{Cr}_{2} \mathrm{~N}$, ferrite, and austenite, along with the diffusion processes, are the factors that control this phase transformation. In the case of intragranular nitrides, they serve as heterogeneous nucleation sites of intragranu$\operatorname{lar} \gamma_{2}$. It was also verified the dissolution of chromium ni- 
trides is favored at temperatures from $1000^{\circ}$ to $1200^{\circ} \mathrm{C}$ (Refs. 24, 53).

\section{Vickers Microhardness and Ultramicrohardness}

The highest hardness values in the as-welded samples can be associated with the fact that the low fraction of austenite causes the supersaturation of nitrogen in the ferrite grain, promoting the $\mathrm{Cr}_{2} \mathrm{~N}$ precipitation (Ref. 45), as seen in Fig. 10B. These particles significantly increase the hardness in the FZ, even with the presence of large ferrite grains and few reformed austenite grains (Ref. 55). In the heat-treated samples, the hardness values are close in both the FZ and BM. The decrease in the FZ hardness after the heat treatments was due to the relief of welding stress, the globularization of the intragranular austenite particles (Ref. 54 ), and the dissolution of the chromium nitrides. On the other hand, the hardness decreases in the BM of the heattreated samples, which was caused by the increase of the ferrite interlamellar spacing and by the relief of stress due to dislocation density decrease. According to Muthupandi et al. (Ref. 54), the microhardness reduction cannot be explained by the $\alpha / \gamma$ ratio changes.

As also verified in previous studies, including Muthupandi et al. (Refs. 54, 56), ultramicrohardness measurements of the ferrite and the austenite in this study have shown that austenite is only slightly harder than ferrite (Table 5). Therefore, a significant difference of hardness in the treated samples was not noticed, even when there was an increase of the austenite fraction with the increase of the heat treatment temperature, because the specific hardness variation of each phase was small. Therefore, the proportion of ferrite and austenite has little effect on the microhardness of the material, as observed in Table 4 for samples L1, L2, L3, and L4. Gunn (Ref. 1) reported that ferrite and austenite do not differ much in composition because the substitutional elements do not have enough time to perform a significant partition during thermal processing. Thus, only the amount of austenite varies, but not the hardness of the $\gamma$ phase.

\section{Corrosion}

As shown previously, the AT100 sample presented a small amount of reformed austenite and abundant precipitation of chromium nitrides - Fig. 10B. It may have caused a chromium depletion around these precipitates and compromised the formation of passive film, which caused a deleterious effect on pitting corrosion resistance in the FZ (Refs. 24, $39,57)$.

The results show the heat treatment at $1150^{\circ} \mathrm{C}$ for 10 min significantly increased the corrosion potential in both the BM and FZ, making the entire weld more noble. This can be explained by the increase in the efficiency of the passive film by the dissolution of the chromium nitrides, which releases the chromium to form the protective oxide by the precipitation of the intragranular austenite, which increases the solubility of $\mathrm{N}$ and $\mathrm{C}$, and by the redistribution of the alloying elements by diffusion (Ref. 7).

\section{Tensile Test}

Some authors claim that welding has a great influence on the mechanical properties of DSSs because of the phase disproportion produced in the procedure and the specific properties of each phase. By comparing the as-received condition with the as-welded sample (AT100) in the tensile tests, this could be observed (see Fig. 17 and Table 7). Some authors have verified an increase of ductility of heat-treated welded joints, and this was observed in this study for the L4 sample with lower porosity. Muthupandi et al. (Ref. 54) suggested the differences in ductility of as-welded and PWHT samples of DSS joints could not be explained only by changes in the ratio of the two phases in the FZ. Possible reasons for significant toughness improvements in PWHT samples, as in the case of hardness, would be stress relief and spheroidization of intragranular austenite particles. In their research, Zhang et al. (Ref. 58) stated that heat treatment at $1080^{\circ} \mathrm{C}$ for 3 min increased the impact toughness at $-40^{\circ} \mathrm{C}$ of the welded joint of the UNS S32750 DSS. This improvement in ductility was attributed to the fact that PWHT helped to restore phase balance, as well as to relieve residual stresses in the weld.

Furthermore, the decrease in mechanical strength and ductility in the AT100 and L4 conditions can be accredited to the ferritic grain growth and changes in austenite and ferrite morphology. De Lacerda et al. (Ref. 59) evaluated the effects of annealing heat treatments on the fatigue behavior of a UNS S31803 DSS at different temperatures $\left(1060^{\circ}\right.$, $1200^{\circ}$, and $\left.1300^{\circ} \mathrm{C}\right)$. The authors reported that, as the annealing temperature increased, the hardness of the ferrite increased, mainly due to the precipitation of chromium nitrides in ferritic grains. Fatigue crack growth was facilitated in the ferritic phase due to its hardening and the reduction of $\alpha / \gamma$ interfaces with the increase in grain size of the two phases (Ref. 59).

In addition to the fraction and morphology phases, literature points out the presence of porosity due to the welding process can also influence the mechanical properties of the workpiece. In this study, in addition to the mechanism that causes the recurrent formation of porosities in the laser welding process as mentioned in the item FZ characterization, the pores may have been formed by poor preparation of the edge, causing an inconsistent weld. If the two plates are not in juxtaposed contact, there is not enough material, and the liquid metal covers the pore, resulting in porosities such as those observed in Fig. 8B. Defects in the weld are one of the main reasons to decrease the mechanical strength of the material (Ref. 40). However, pores are stress concentrators, and, thus, for the same applied engineering stress, the real stress around the defects is considerably higher, so the yield and ultimate strength (which use the concept of engineering stress) are smaller. The porosity is a defect in the weld bead, deteriorating its mechanical properties and decreasing its plastic strain capability. In Fig. 20, it is noticed that around the pores, the fracture presented a brittle behavior (presence of cleavage facets). This could explain the poorer performance of the specimen with higher porosity in the weld. Because the pores are sources of stress concentration, this justifies the brittle behavior in the vicinity of pores and the overall ductility loss of the sample. 
The material in the as-received condition presented the best tensile behavior in relation to the as-welded material and the heat-treated material. The AT100 sample, which has a predominantly ferritic microstructure with the presence of $\mathrm{Cr}_{2} \mathrm{~N}$ precipitates, attained higher values of yield strength and lower values of total strain (Refs. 59,60 ) than the L4 sample with lower porosity. Moreover, the fact that ferrite hardness is lower than austenite hardness in the as-welded sample (see Table 5), mainly the ferritic phase, contributed to the reduction of the mechanical strength of the material. The decrease in the tensile properties of the as-welded specimen can be attributed to the large volumetric fraction of ferrite, the change in the morphology of the two phases, and the precipitation of chromium nitrides (Refs. 59, 60).

When comparing the samples L4 (with higher porosity) and L4 (with lower porosity), they presented significantly different yield and strength limits, area reduction, and total strain, even though they have a similar proportion of ferrite and austenite phases. These results indicate that even if there is an adequacy of the austenite and ferrite fraction, and the dissolution of chromium nitrides during the heat treatment, the specimens in which the weld presented a higher porosity in the fractured surface presented a behavior close to the specimen without PWHT. When comparing the L4 sample (with lower porosity) with the as-received condition, despite having similar ferrite and austenite proportions, the mechanical properties are different (see Fig. 17 and Table 7). Thus, despite the similar phase fractions, the grain size, phase morphology, and porosity are very relevant factors in the tensile behavior of the welded joint of duplex stainless steel. It follows that simply restoring the phase fraction of the DSS does not guarantee restoration of the tensile properties of welded joints.

\section{Conclusion}

The high cooling rates characteristic of the laser welding process provided a mostly ferritic structure, as little austenite was reformed during the cooling process. In the condition with higher heat input $(100 \mathrm{~J} / \mathrm{mm})$ and consequently, lower cooling rate, the largest fraction of reformed austenite was obtained (3.5\%), while in the condition with the lowest heat input (50 $\mathrm{J} / \mathrm{mm}$ ), only $1.8 \%$ of the austenite volumetric fraction was obtained. These values are well below what is desirable, which is around $50 \%$.

In both laser welding conditions, there was precipitation of chromium nitrides due to the fast cooling of the weld bead. Thus, diffusion of nitrogen is difficult and precipitates in the form of $\mathrm{Cr}_{2} \mathrm{~N}$, inside the ferritic grain or within its boundaries.

The heat treatment after laser welding provided a readjustment of the volumetric fraction in the $\mathrm{FZ}$ at $1150^{\circ} \mathrm{C}$ for $10 \mathrm{~min}$, obtaining a volume fraction of $44.2 \%$, close to the as-received sample. Also, the presence of chromium nitrides via the OM was not noticed.

As-welded samples presented a hardness increase in the $\mathrm{FZ}$ in relation to the $\mathrm{BM}$ due to the precipitation of chromium nitrides. After heat treatment, the hardness values were very close in both the FZ and BM. The FZ hardness decrease is attributed to stress-relieving globularization of the intragranular austenite particles and dissolution of chromium nitrides.
The as-welded sample (AT100) presented the worst performance in the corrosion test compared to the postweld heat-treated sample (L4) because of the presence of $\mathrm{Cr}_{2} \mathrm{~N}$. Heat treatment at $1150^{\circ} \mathrm{C}$ for 10 min considerably improved the corrosion properties of the welded joint. There was an efficiency increase of the passive film because of the dissolution of the chromium nitrides.

Phase balance by heat treatment tends to improve the tensile behavior of the welded joint. However, phase grain sizes, phase morphology, and porosity are very relevant factors that influence the tensile behavior of the welded joint of DSSl. The results show there is a great influence of the weld quality on the mechanical properties of the workpiece, besides the microstructure of the material. The presence of discontinuities, such as porosities in the weld, greatly impair the mechanical strength of the material.

\section{Acknowledgments}

The authors acknowledge the Coordenação de Aperfeiçoamento de Pessoal de Nível Superior and the Conselho Nacional de Desenvolvimento Científico e Tecnológico for the financial support. Also, the authors would like to thank Aperam South America for supplying plates of UNS S32304 duplex stainless steel for the development of this work.

\section{References}

1. Gunn, R. N. 1997. Duplex Stainless Steels: Microstructure, Properties and Applications. Cambridge: Woodhead Publishing.

2. Silva, A. L. V. da C. E. and Mei, P. R. 2010. Aços e Ligas Especiais. 664. São Paulo: Blucher.

3. Davis, J. R. 1998. Metals Handbook Desk Edition. Materials Park: ASM International.

4. Pohl, M., Storz, O., and Glogowski, T. 2007. Effect of intermetallic precipitations on the properties of duplex stainless steel. Materials Characterization 58(1): 65-71. DOI: 10.1016/j.matchar. 2006.03.015

5. Nilsson, J.-O. 1992. Super duplex stainless steels. Materials Science and Technology 8(8): 685-700. DOI: 10.1179/mst.1992. 8.8.685

6. Kordatos, J. D., Fourlaris, G., and Papadimitriou, G. 2001. The effect of cooling rate on the mechanical and corrosion properties of SAF 2205 (UNS 31803) duplex stainless steel welds. Scripta Materialia 44(3): 401-408. DOI: 10.1016/S1359-6462 (00)00613-8

7. Ramirez, A. J. 2001. Precipitação de fases intermetálicas e austenita secundária na ZAC de soldagens multipasse de aços. PhD dissertation. São Paulo, SP, Escola Politécnica da Universidade de São Paulo.

8. Blondeau, R. 2008. Metallurgy and Mechanics of Welding: Processes and Industrial Applications. Hoboken: Wiley.

9. Ramirez, A. J., Lippold, J. C., and Brandi, S. D. 2003. The relationship between chromium nitride and secondary austenite precipitation in duplex stainless steels. Metallurgical and Materials Transactions A 34(8): 1575-1597. DOI: 10.1007/s11661-003-0304-9

10. Liu, H., and Jin, X. 2012. Secondary austenite morphologies in fusion zone of welded joint after postweld heat treatment with a continuous wave laser. Journal of Materials Science \& Technology 28(3): 249-254. DOI: 10.1016/S1005-0302(12)60049-8

11. Mourad, A.-H. I., Khourshid, A., and Sharef, T. 2012. Gas 
tungsten arc and laser beam welding processes effects on duplex stainless steel 2205 properties. Materials Science and Engineering A 549: 105-113. DOI: 10.1016/j.msea.2012.04.012

12. Saravanan, S., Raghukandan, K., and Sivagurumanikandan, N. 2017. Pulsed Nd: YAG laser welding and subsequent post-weld heat treatment on super duplex stainless steel. Journal of Manufacturing Processes 25: 284-289. DOI: 10.1016/j.jmapro.2016.

12.015

13. Pekkarinen, J., and Kujanpää, V. 2010. The effects of laser welding parameters on the microstructure of ferritic and duplex stainless steels welds. Physics Procedia 5(Part 1): 517-523. DOI: 10.1016/j.phpro.2010.08.175

14. Mohammed, G. R., Ishak, M., Aqida, S. N., and Abdulhadi, H. A. 2017. Effects of heat input on microstructure, corrosion and mechanical characteristics of welded austenitic and duplex stainless steels: A review. Metals 7(2): 39. DOI: 10.3390/met7020039

15. Keskitalo, M., Mäntyjärvi, K., Sundqvist, J., Powell, J., and Kaplan, A. F. H. 2015. Laser welding of duplex stainless steel with nitrogen as shielding gas. Journal of Materials Processing Technology 216: 381-384. DOI: 10.1016/j.jmatprotec.2014.10.004

16. Enhanced Machine Controller - EMC2. FSF: GNU/Linux, 2008.

17. Pont, D., and Guichard., T. 1995. Sysweld ${ }^{\circledR}$ : Welding and Heat Treatment Modelling Tools BT - Computational Mechanics '95. In Computational Mechanics '95, 248-253. Springer Berlin Heidelberg. DOI: 10.1007/978-3-642-79654-8_41

18. Lima, M., and Wagniére, J. D. 1998. Determinación de la absorción de haz láser en ensayos de refusión en régimen continuo. Revista de Metalurgia 34(2): 131-134. DOI: 10.3989/revmetalm. 1998.v34.i2.675

19. Silva, E. M. R., Monteiro, W. A., and Rossi, W. 2000. Absorption of Nd:YAG laser beam by metallic alloys. Journal of Materials Science Letters 19(23): 2095-2097. DOI: 10.1023/

A:1026750004296

20. ASTM E3-11, Standard Guide for Preparation of Metallographic Specimens. 2017. ASTM International, West Conshohocken, Pa. DOI: 10.1520/E0003-11R17

21. Zhang, Z., Zhao, H., Zhang, H., Hu, J., and Jin, J. 2017. Microstructure evolution and pitting corrosion behavior of UNSS32750 super duplex stainless steel welds after short-time heat treatment. Corrosion Science 121: 22-31. DOI: 10.1016/ j.corsci.2017.02.006

22. Guo, Y., Sun, T., Hu, J., Jiang, Y., Jiang, L., and Li, J. 2016. Microstructure evolution and pitting corrosion resistance of the gleeble-simulated heat-affected zone of a newly developed lean duplex stainless steel 2002. Journal of Alloys and Compounds 658: 1031-1040. DOI: 10.1016/j.jallcom.2015.10.218

23. Zhang, Z., Wang, Z., Jiang, Y., Tan, H., Han, D., Guo, Y., and Li, J. 2012. Effect of post-weld heat treatment on microstructure evolution and pitting corrosion behavior of UNS S31803 duplex stainless steel welds. Corrosion Science 62: 42-50. DOI: 10.1016/ j.corsci.2012.04.047

24. Tan, H., Wang, Z., Jiang, Y., Han, D., Hong J., Chen, L., Jiang, L., and Li, J. 2011. Annealing temperature effect on the pitting corrosion resistance of plasma arc welded joints of duplex stainless steel UNS S32304 in 1.0M NaCl. Corrosion Science 53(6): 2191-2200. DOI: 10.1016/j.corsci.2011.02.041

25. Tan, H., Jiang, Y., Deng, B., Sun, T., Xu, J., and Li, J. 2009. Effect of annealing temperature on the pitting corrosion resistance of super duplex stainless steel UNS S32750. Materials Characterization 60(9): 1049-1054. DOI: 10.1016/j.matchar.2009.04.009

26. Hosseini, V. A., Hurtig, K., Eyzop, D., Östberg, A., Janiak, P., and Karlsson, L. 2019. Ferrite content measurement in super duplex stainless steel welds. Weld World 63(2): 551-563. DOI: 10.1007/s40194-018-00681-1

27. ASTM A1084-15a, Standard Test Method for Detecting Detrimental Phases in Lean Duplex Austenitic/Ferritic Stainless Steels.
2015. ASTM International, West Conshohocken, Pa. DOI: 10.1520/A1084-15A

28. Kauss, N., Heyn, A., Halle, T., and Rosemann, P. 2019. Detection of sensitisation on aged lean duplex stainless steel with different electrochemical methods. Electrochimica Acta 317: 17-24. DOI: 10.1016/j.electacta.2019.05.081

29. Ascari, A., Fortunato, A., Orazi, L., and Campana, G. 2012. The influence of process parameters on porosity formation in hybrid LASER-GMA welding of AA6082 aluminum alloy. Optics \& Laser Technology 44(5): 1485-1490. DOI: 10.1016/j.optlastec. 2011.12.014

30. ASTM E466-15, Standard Practice for Conducting Force Controlled Constant Amplitude Axial Fatigue Tests of Metallic Materials. 2015. ASTM International, West Conshohocken, Pa. DOI:

10.1520/E0466-15

31. Haghdadi, N., Laleh, M., Kosari, A., Moayed, M. H., Cizek, P., Hodgson, P. D., and Beladi, H. 2019. The effect of phase transformation route on the intergranular corrosion susceptibility of 2205 duplex stainless steel. Materials Letters 238: 26-30. DOI: 10.1016/j.matlet.2018.11.143

32. Jinlong, L., Tongxiang, L., Limin, D., and Chen, W. 2016. Influence of sensitization on microstructure and passive property of AISI 2205 duplex stainless steel. Corrosion Science 104: 144-151. DOI: 10.1016/j.corsci.2015.12.005

33. Yang, Y., Wang, Z., Tan, H., Hong, J., Jiang, Y., Jiang, L., and Li, J. 2012. Effect of a brief post-weld heat treatment on the microstructure evolution and pitting corrosion of laser beam welded UNS S31803 duplex stainless steel. Corrosion Science 65: 472-480. DOI: 10.1016/j.corsci.2012.08.054

34. Zhang, L., Zhang, W., Jiang, Y., Deng, B., Sun, D., and Li, J. 2009. Influence of annealing treatment on the corrosion resistance of lean duplex stainless steel 2101. Electrochimica Acta 54(23): 5378-5392. DOI: 10.1016/j.electacta.2009.04.023

35. Varbai, B., Adonyi, Y., Baumer, R., Pickle, T., Dobránszky, J., and Májlinger, K. 2019. Weldability of duplex stainless steels Thermal cycle and nitrogen effects. Welding Journal 98(3): 78-s to 87-s. DOI: 10.29391/2019.98.006

36. Lai, R., Caia, Y., Wu, Y., Li, F., and Hua, X. 2016. Influence of absorbed nitrogen on microstructure and corrosion resistance of 2205 duplex stainless steel joint processed by fiber laser welding. Journal of Materials Processing Technology 231: 397-405. DOI: 10.1016/j.jmatprotec.2016.01.016

37. Oxford Instruments AZtec system. Advances in EBSD. Accessed by November 22, 2019. ebsd.com/solving-problems-withebsd/ebsd-advancement

38. Hertzman, S., Brolund, B., and Ferreira, P. J. 1997. An experimental and theoretical study of heat-affected zone austenite reformation in three duplex stainless steels. Metallurgical and Materials Transactions A 28(2): 277-285. https://doi.org/10.1007/s11661997-0130-6

39. Chen, L., Tan, H., Wang, Z., Li, J., and Jiang, Y. 2012. Influence of cooling rate on microstructure evolution and pitting corrosion resistance in the simulated heat-affected zone of 2304 duplex stainless steels. Corrosion Science 58(5): 168-174. DOI: 10.1016/ j.corsci.2012.01.018

40. Hu, S., Zheng, D., Zhao, G., Li, G., and Tang, H. 2018. The effect of welded joint properties on the surface characteristics of laser-welded 2205 duplex stainless steel. Advances in Mechanical Engineering 10(9). DOI: 10.1177/1687814018797449

41. Zhao, Y., Zhang, Y., Hu, W., and Lai, X. 2012. Optimization of laser welding thin-gage galvanized steel via response surface methodology. Optics and Lasers in Engineering 50(9): 1267-1273. DOI: 10.1016/j.optlaseng.2012.03.010

42. Lippold, J. C., and Kotecki, D. J. 2005. Welding Metallurgy and Weldability of Stainless Steels. Hoboken: John Wiley \& Sons Inc.

43. Perren, R. A, Suter, T., Solenthaler, C., Gullo, G., Uggowitzer, P. J., Böhni, H., and Speidel, M. O. 2001. Corrosion resistance of su- 
per duplex stainless steels in chloride ion containing environments: Investigations by means of a new microelectrochemical method. Corrosion Science 43(4): 727-745. DOI: 10.1016/S0010938X(00)00088-3

44. Bettini, E., Kivisäkk, U., Leygraf, C., and Pan, J. 2013. Study of corrosion behavior of a $22 \% \mathrm{Cr}$ duplex stainless steel: Influence of nano-sized chromium nitrides and exposure temperature. Electrochimica Acta 113: 280-289. DOI: 10.1016/j.electacta.2013. 09.056

45. Magalhães, C. H. X. M., de Faria, G. L., Lagoeiro, L. E., and Silva, J. D. 2017. Characterization of the austenite reformation mechanisms as a function of the initial ferritic state in a UNS S32304 duplex stainless steel. Materials Research 20(6): 14701479. DOI: $10.1590 / 1980-5373-m r-2016-1122$

46. Fomin, F., and Kashaev, N. 2017. Influence of porosity on the high cycle fatigue behaviour of laser beam welded Ti-6Al-4V butt joints. Procedia Structural Integrity 7: 415-422. DOI: 10.1016/ j.prostr.2017.11.107

47. Fomin, F., Ventzke, V., Dorn, F., Levichev, N., and Kashaev, N. 2017. Effect of microstructure transformations on fatigue properties of laser beam welded Ti-6Al-4V butt joints subjected to postweld heat treatment. In Study of Grain Boundary Character, i: 13. InTech. DOI: 10.5772/66178

48. Seto, N., Katayama, S., and Matsunawa, A. 2001. Porosity formation mechanism and reduction method in $\mathrm{CO}_{2}$ laser welding of stainless steel. Quarterly Journal of The Japan Welding Society 19(4): 600-609. DOI: 10.2207/qjjws.19.600

49. Meng, W., Li, Z., Lu, F., Wu, Y., Chen, J., and Katayama, S. 2014. Porosity formation mechanism and its prevention in laser lap welding for t-joints. Journal of Materials Processing Technology 214(8): 1658-64. DOI: 10.1016/j.jmatprotec.2014.03.011

50. Zhao, H., Niu, W., Zhang, B., Lei, Y., Kodama, M., and Ishide, T. 2011. Modelling of keyhole dynamics and porosity formation considering the adaptive keyhole shape and three-phase coupling during deep-penetration laser welding. Journal of Physics D: Applied Physics 44(48). DOI: 10.1088/0022-3727/44/48/485302

51. Fotovvati, B., Wayne, S. F., Lewis, G., and Asadi, E. 2018. A review on melt-pool characteristics in laser welding of metals. Hindawi Ltd. Advances in Materials Science and Engineering. DOI: $10.1155 / 2018 / 4920718$

52. Zhou, J., and Tsai, H.-L. 2007. Porosity formation and prevention in pulsed laser welding. Journal of Heat Transfer 129(8): 1014-1024. DOI: 10.1115/1.2724846

53. Zhang, Z., Jing, H., Xu, L., Han, Y., Zhao, L., and Lv, X. 2018. Effect of post-weld heat treatment on microstructure evolution and pitting corrosion resistance of electron beam-welded duplex stainless steel. Corrosion Science 141(135): 30-45. DOI: 10.1016/j.corsci. 2018.06.030
54. Muthupandi, V., Bala Srinivasan, P., Seshadri, S. K., and Sundaresan, S. 2003. Effect of weld metal chemistry and heat input on the structure and properties of duplex stainless steel welds. Materials Science and Engineering A 358(1-2): 9-16. DOI: 10.1016/ S0921-5093(03)00077-7

55. Tavares, S. S. M., Terra, V. F., Pardal, J. M., and Cindra Fonseca, M. P. 2005. Influence of the microstructure on the toughness of a duplex stainless steel UNS S31803. Journal of Materials Science 40(1): 145-154. DOI: 10.1007/s10853-005-5700-7

56. Muthupandi, V., Bala Srinivasan, P., Shankar, V., Seshadri, S. K., and Sundaresan, S. 2005. Effect of nickel and nitrogen addition on the microstructure and mechanical properties of power beam processed duplex stainless steel (UNS 31803) weld metals. Materials Letters 59(18): 2305-2309. DOI: 10.1016/j.matlet.2005.03.010

57. El-Batahgy, A., Khourshid, A.-F., and Sharef, T. 2011. Effect of laser beam welding parameters on microstructure and properties of duplex stainless steel. Materials Sciences and Applications 02(10): 1443-1451. DOI: 10.4236/msa.2011.210195

58. Zhang, Z., Zhang, H., Hu, J., Qi, X., Bian, Y., Shen, A., Xu, P., and Zhao, Y. 2018. Microstructure evolution and mechanical properties of briefly heat-treated SAF 2507 super duplex stainless steel welds. Construction and Building Materials 168(4): 338-345. DOI: 10.1016/j.conbuildmat.2018.02.143

59. de Lacerda, J. C., Cândido, L. C., and Godefroid, L. B. 2015. Effect of volume fraction of phases and precipitates on the mechanical behavior of UNS S31803 duplex stainless steel. International Journal of Fatigue 74: 81-87. DOI: 10.1016/j.ijfatigue.2014.12.015

60. Badji, R., Bouabdallah, M., Bacroix, B., Kahloun, C., Belkessa, B., and Maza, H. 2008. Phase transformation and mechanical behavior in annealed 2205 duplex stainless steel welds. Materials Characterization 59(4): 447-453. DOI: 10.1016/ j.matchar.2007.03.004
APARECIDA SILVA MAGALHÃES, CHARLES HENRIQUE XAVIER MORAIS MAGALHÃES, LEONARDO BARBOSA GODEFROID, and GERALDO LÚCIO DE FARIA (geraldolfaria@yahoo.com.br) are with the Department of Metallurgical and Materials Engineering, Federal University of Ouro Preto, Ouro Preto, MG, Brazil. MILTON SERGIO FERNANDES DE LIMA is with the Institute for Advanced Studies, São José dos Campos, Brazil. JULIANE CRUZ and RODNEI BERTAZZOLI are with the Department of Mechanical Engineering and Aeronautics, Technological Institute of Aero- nautics, São José dos Campos, Brazil. BERTAZZOLI is also with the Brazilian Nanotechnology National Laboratory, Brazilian Center for Research in Energy and Materials, Campinas, Brazil.

\section{Authors: Submit Research Papers Online}

Peer review of research papers is now managed through an online sytem using Editorial Manager software. Papers can be submitted into the system directly from the Welding Journal page on the AWS website (aws.org) by clicking on "submit papers." You can also access the new site directly at editorialmanager.com/wj/. Follow the instructions to register or log in. This online system streamlines the review process, and makes it easier to submit papers and track their progress. By publishing in the Welding Journal, more than 70,000 members will receive the results of your research.

Additionally, your full paper is posted on the American Welding Society website for FREE access around the globe. There are no page charges, and articles are published in full color. By far, the most people, at the least cost, will recognize your research when you publish in the worldwide-respected Welding Journal. 